Research Article

\title{
User Acceptance of Internet of Vehicles Services: Empirical Findings of Partial Least Square Structural Equation Modeling (PLS-SEM) and Fuzzy Sets Qualitative Comparative Analysis (fsQCA)
}

\author{
Yikai Liang $\mathbb{D}$, Guijie Zhang $\mathbb{D}$, Feng Xu $(\mathbb{D}$, and Weijie Wang $\mathbb{D}$ \\ School of Management Science and Engineering, Shandong University of Finance and Economics, Jinan 250014, China \\ Correspondence should be addressed to Yikai Liang; yikailiang@qq.com
}

Received 16 October 2020; Revised 9 November 2020; Accepted 11 November 2020; Published 12 December 2020

Academic Editor: Peter Brida

Copyright (C) 2020 Yikai Liang et al. This is an open access article distributed under the Creative Commons Attribution License, which permits unrestricted use, distribution, and reproduction in any medium, provided the original work is properly cited.

Recently, IoV-based services and vehicles have come to the forefront as part of the growing market for the automobile industry. Since IoV-based services and vehicles were introduced, they have been expected to grow rapidly. However, contrary to optimistic expectations for future market growth, the IoV-based services and vehicles market has appeared to hit a roadblock and remains at an early market stage. Therefore, research of the determinants leading to consumers' intention to accept and purchase IoV-based services and vehicles is significant for either academics or practitioners. Drawing upon the extended unified theory of acceptance and use of technology acceptance model (UTAUT2), the perceived risk theory, and the initial trust model, we developed an integrated conceptual model and explored what and how various determinant antecedent conditions fit together on consumer intention to accept IoV-based services and vehicles. The proposed model and hypotheses were assessed by both symmetric (partial least square structural equation modeling, PLS-SEM) and asymmetric (fsQCA) approaches using online survey datasets with 362 Chinese consumers. The findings suggest that PLS-SEM and fsQCA are complementary analytical techniques providing comparable results. PLS-SEM results indicate that performance expectancy, price value, habit, and initial trust have significant effects on behavioral intention to accept IoV services. Despite other determinants, e.g., effort expectancy, social influence, facilitating conditions, hedonic motivation, and perceived risk, have no significant effect. FsQCA results reveal twelve different configurations of determinants resulting in a high level of behavioral intention to accept IoV services, and eight causal paths equifinally leading to the negation of behavioral intention to accept IoV services. These findings suggest that several conditions that were not significant in PLS-SEM are sufficient conditions when combined with other conditions. This study enriches relevant research studies on IoV-based services acceptance and provides relevant insights and marketing suggestions for incentivizing consumers to accept the IoV-based services.

\section{Introduction}

In recent years, connected autonomous vehicle (CAVs) or called intelligent connected vehicles, as the core component of the intelligent transportation system (ITS) and a node of Internet of Vehicles (IoV) system [1], have become one of the most popular research fields in network and intelligent transportation system, as well as attracted huge investments from the automotive manufacturers. Various IoV-based services and location-based services of the connected autonomous vehicle, e.g., car navigation systems, vehicle information systems, advanced driver assistance, humancomputer interaction, and car infotainment systems, play important roles in making transportation safer, cleaner, and more comfortable $[1,2]$. While IoV-based services have a wide range of benefits in terms of safety, energy efficiency, environment improvement, increased mobility, and more entertainment in driving [3-10], such benefits may not be realized until IoV-based services are widely accepted and used by a critical mass of consumers [11-15]. Recent surveys 
have shown that the consumers' intention to accept or purchase IoV-based services is generally low $\mathrm{Wu}$ et al. [3]. Therefore, it is significant to explore the determinants of consumers' intention to accept and purchase IoV-based services [16].

With ongoing technological advances in automation and connectivity, several studies have been discussed concerning IoV-based services in recent years that have concentrated on different issues $[1,17]$, such as the concept of IoV $[18,19]$, architecture (four layers including vehicle network environment sensing and control layer, network access and transport layer, coordinative computing control layer, and application layer) $[20,21]$, and key technologies for $\operatorname{IoV}[22,23]$, as well as barriers and determinants of IoV-based services and vehicles adoption [24, 25]. Numerous studies have investigated key factors for consumers' willingness-to-pay (WTP) and the adoption of IoV-based services and vehicles from the perspectives of various innovation adoption theories $[6,26]$. However, almost all of the empirical studies have been grounded in the use of the conventional symmetric-based techniques, including multiple regression model [13, 27-29], structural equation modeling (SEM) $[11,14,15,30,31]$, and partial least square (PLS) $[10,12,31-35]$, to explore the relationships between independent variables (IV) and dependent variables (DV). These conventional techniques are variableoriented that focus on the "net effect" of IV on DV, while excluding possible asymmetric relations between variables [36], leading to the correlation and significance might vary depending on the variables the model includes. In real-life scenarios, a viable outcome often depends on combinations of several antecedents that collectively form what is referred to as an algorithm in the asymmetric method [37]. Therefore, qualitative comparative analysis (QCA), as a holistic approach, has been recommended for facilitating the analysis of complex causality and logical relations among combinations of conditions and an outcome, allowing researchers to examine multiple causal paths that lead to the same outcome [38-40].

To fill this gap, in the study, we answer the calls for the application of the holistic approach to understand the determinants' configurations on consumers' behavioral intention to accept IoV-based services. Therefore, based on the review of studies related to the acceptance of IoV-based services and vehicles, we develop an integrated theoretical model including the extended unified theory of acceptance and use of technology (UTAUT2) [41] with the constructs of perceived risk from perceived risk theory [42] and initial trust from the initial trust model [43]. These factors employed have been extensively used in innovation adoption studies and are appropriate for explaining IoV-based services' acceptance. This integrated model makes up for the inadequate explanation of the individual behavior adopted by a single model. Using online survey datasets with 362 Chinese consumers, we use both symmetric (PLS-SEM) and asymmetric (fsQCA) methods, to explore the role of the above determinants on the intention to accept IoV-based services. Our study involves some antecedents not analyzed in the literature, and it starts by analyzing the net effects of each antecedent with PLS-SEM. Moreover, to provide a more accurate understanding of the complex reality associated with the various determinants and behavioral intention to accept IoV-based services, the configurations of causal factors are analyzed by fsQCA for explaining the complex intention that the PLS-SEM does not capture [44]. FsQCA can not only explore how the antecedent factors combine to produce multiple alternative paths that can successfully lead to this intention but also assume causal asymmetry to identify the paths that explain the negation of the intention. The findings of PLS-SEM and fsQCA provide relevant insights and marketing suggestions for incentivizing consumers to accept and purchase IoV-based services.

The study is organized as follows. Section 2 provides literature reviews for the research model. Section 3 presents our conceptual model and hypotheses. Section 4 explains the measurement and data used in the empirical analysis. Section 5 presents the results of the empirical analysis by PLS-SEM and fsQCA. The key findings, theoretical implications, managerial implications, and limitations of the present study are discussed in Section 6. Finally, Section 7 is the conclusions of this study.

\section{Literature Review and Theoretical Basis}

2.1. The Definition and Adoption of IoV-Based Services and Vehicles. IoV as an important part of the wisdom city is a complex integrated network system [18], which connects different people within vehicles, different vehicles, and different environment entries in cities. As an important branch of IoT in the transportation field, IoV covers a wide range of technologies and applications, including intelligent transportation, vehicular information service, modern information and communications technology, and automotive electronics. However, owing to different understandings of the connotation of $\mathrm{IoV}$ in various research fields, there is no uniform definition of IoV [18]. IoV is different from telematics, vehicle ad hoc networks, and intelligent transportation, in which vehicles like phones can run within the whole network and obtain various services by swarm intelligent computing with people, vehicles, and environments.

IoV-based services and vehicles introduce all sorts of different benefits such as safety, energy efficiency, environment improvement, increased mobility, and more entertainment in driving [3-5, 14]. However, there still exist several concerns about IoV-based services and vehicles, such as the relatively higher prices and maintenance costs compared with existing vehicles, performance, and safety issues when operating in complex conditions, impeding the adoption of IoV-based services and vehicles [14]. Therefore, to ensure the social acceptability of IoV-based services and vehicles, numerous studies use technology adoption theories to explore the determinants of consumers' intention to accept and purchase IoV-based services and vehicles $[6,26]$. Table 1 summarizes previous studies on IoV-based services and vehicle acceptance based on a theoretical perspective of technology acceptance.

As shown in Table 1, previous studies have sought to explain the acceptance of various concepts of IoV-based services and vehicles, such as autonomous vehicles, connected vehicles, in-vehicle infotainment systems, and autonomous shuttle services. From a theoretical point of view, 
TABLe 1: Related studies on IoV-based services acceptance.

\begin{tabular}{|c|c|c|c|c|c|}
\hline References & Theory & $\begin{array}{l}\text { Types of IoV- } \\
\text { based services }\end{array}$ & $\begin{array}{l}\text { Method (data } \\
\text { collection and } \\
\text { analysis) }\end{array}$ & $\begin{array}{l}\text { Antecedent conditions (IV) } \\
\text { and outcome (DV) }\end{array}$ & Key findings \\
\hline [35] & TAM & $\begin{array}{l}\text { Connected } \\
\text { vehicles }\end{array}$ & $\begin{array}{c}\text { Online survey (116 } \\
\text { participants t) and } \\
\text { PLS-SEM }\end{array}$ & $\begin{array}{l}\text { Perceived usefulness (PU), } \\
\text { perceived ease of use (PEOU), } \\
\text { attitude, privacy concerns, } \\
\text { privacy risk, trust in provider, } \\
\text { information control, social } \\
\text { norm, and behavioral } \\
\text { intention (BI) to use }\end{array}$ & $\begin{array}{c}\text { Attitude and social norm have } \\
\text { a significant positive effect on } \\
\text { BI, while PU, privacy risk, and } \\
\text { trust in provider have no } \\
\text { effect }\end{array}$ \\
\hline
\end{tabular}

Mass media enhances potential users' self-efficacy of fully AVs, while social media

Social cognitive theory, TPB, prospect theory, and value perception theory
Fully autonomous vehicles
Mass media, social media, Survey (355 samples self-efficacy, subjective norms in Beijing, China) and PLS-SEM
(SN), PU, perceived risks

(PR), and adoption intention to private AVs and public AVs strengthens SN; both PU and $\mathrm{PR}$ of AVs are perceived simultaneously via mass media, whereas PR can be significantly eliminated by social media; all constructs of self-efficacy, SN, PU, and PR are verified to drive intention to use AVs

Individuals' mindset, subjective customs, and

Attitude, SN, behavioral control, cognitive and emotive factors (comparative advantage, compatibility, complexity, and hedonic motivation), and acceptance
[14] TPB

[45] UTAUT2

Autonomous delivery vehicles

Online survey (501

German) and SEM
Performance expectancy (PE), effort expectancy (EE), social influence (SI), facilitating conditions (FC), hedonic motivation, price sensitivity, $\mathrm{PR}$, and $\mathrm{BI}$
Autonomous shuttle services
Survey $(700$

respondents in

Taiwan) and SEM
PU, PEOU, attitude, trust, perceived enjoyment, and use intention

behavioral influence directly affect AVs acceptance; comparative advantage, compatibility, complexity, and hedonic motivation indirectly affect AVs acceptance

Price sensitivity is the strongest predictor of $\mathrm{BI}$, followed by $\mathrm{PE}$, hedonic motivation, PR, SI, and FC, whereas no effect could be found for $\mathrm{EE}$

PU, PEOU, trust, and perceived enjoyment positively affect attitude; PU, trust, and attitude positively affect use intention

PEOU positively affect $\mathrm{PU}$; PU and perceived safety risk positively affect initial trust;

PEOU and initial trust positively affect attitude; PU and attitude positively affect

Face-to-face survey

Shenzhen, China) and SEM risk, perceived privacy risk, using, and BI BI

Trust has direct and indirect

effects on AV acceptance; PB is more influential than $\mathrm{PR}$ in affecting $\mathrm{AV}$ acceptance and also in mediating the trustacceptability relationship

Relative advantage positively affects PU; self-efficacy positively affects PEOU; selfefficacy, psychological ownership, PR, and PU affect intention to use autonomous 
TABle 1: Continued.

\begin{tabular}{cccc}
\hline References Theory & $\begin{array}{c}\text { Types of IoV- } \\
\text { based services }\end{array}$ & $\begin{array}{c}\text { Method (data } \\
\text { collection and } \\
\text { analysis) }\end{array}$ & $\begin{array}{c}\text { Antecedent conditions (IV) } \\
\text { and outcome (DV) }\end{array}$ \\
\hline
\end{tabular}

[48] TAM

Autonomous electric bus

Online survey (268 passengers in Germany) and SEM
PU, PEOU, ATU, individual differences, social impacts, systems characteristics, and intention to use

Desire to exert control, SN, perceived enjoyment, PU, and PEOU positively affect ATU; trust, SN, price evaluation, and ATU positively affect intention to use

Online survey (268 passengers in

TAM and the life- Self-driving oriented approach public bus
Germany) and PLSSEM
PU, PEOU, ATU, life choices, subjective well-being, factors of travel quality, life domains, and intention to use

Attitude towards

Online survey (1177 participants in

Europe, China, and

North America) and PLS-SEM environmental protection, innovativeness, perceived enjoyment, objective usability, PU, PEOU, ATU, and BI
Automated

vehicles

Trust, price evaluation, social network, residence, family budget, PU, and ATU positively affect intention to use

Perceived enjoyment and objective usability positively affect both PU and PEOU; PU and PEOU positively affect ATU; ATU positively affects BI

Environmental concern, green $\mathrm{PU}$, and $\mathrm{PEOU}$

Online survey (470 respondents in China)
Environmental concern, green PU, PEOU, and BI electric vehicles

[2]

TAM

$$
\text { and SEM }
$$


TABLE 1: Continued.

\begin{tabular}{|c|c|c|c|c|c|}
\hline References & Theory & $\begin{array}{l}\text { Types of IoV- } \\
\text { based services }\end{array}$ & $\begin{array}{l}\text { Method (data } \\
\text { collection and } \\
\text { analysis) } \\
\end{array}$ & $\begin{array}{l}\text { Antecedent conditions (IV) } \\
\text { and outcome (DV) }\end{array}$ & Key findings \\
\hline$[7]$ & UTAUT & $\begin{array}{l}\text { Autonomous } \\
\text { car }\end{array}$ & $\begin{array}{l}\text { Online survey ( } 241 \\
\text { respondents in } \\
\text { France) and SEM and } \\
\text { multigroup analysis }\end{array}$ & $\begin{array}{c}\mathrm{PE}, \mathrm{EE}, \mathrm{SI} \text {, consumer } \\
\text { innovativeness, and purchase } \\
\text { intention }\end{array}$ & $\begin{array}{c}\text { PE, EE, and SI positively affect } \\
\text { purchase intentions; } \\
\text { consumer innovativeness } \\
\text { moderates the relationships } \\
\text { between the constructs }\end{array}$ \\
\hline$[13]$ & TAM & $\begin{array}{l}\text { Autonomous } \\
\text { driving }\end{array}$ & $\begin{array}{l}\text { Web-based survey } \\
(483 \text { respondents in } \\
\text { Greece) and multiple } \\
\text { regression }\end{array}$ & $\begin{array}{c}\text { PU, PEOU, perceived trust, SI, } \\
\text { and BI to have AVs }\end{array}$ & $\begin{array}{l}\text { PU, PEOU, perceived trust, } \\
\text { and SI positively affect BI }\end{array}$ \\
\hline [29] & UTAUT & $\begin{array}{l}\text { Automated road } \\
\text { transport } \\
\text { systems }\end{array}$ & $\begin{array}{l}\text { Survey (315 } \\
\text { participants in } \\
\text { Greece) and } \\
\text { hierarchical multiple } \\
\text { regression }\end{array}$ & $\begin{array}{l}\mathrm{PE}, \mathrm{EE}, \mathrm{SI}, \mathrm{FC} \text {, hedonic } \\
\text { motivation, and } \mathrm{BI}\end{array}$ & $\begin{array}{c}\text { PE, SI, FC, and hedonic } \\
\text { motivation positively affect BI }\end{array}$ \\
\hline$[28]$ & UTAUT & $\begin{array}{l}\text { Automated road } \\
\text { transport } \\
\text { systems }\end{array}$ & $\begin{array}{l}\text { Survey (349 } \\
\text { respondents from } \\
\text { France and } \\
\text { Switzerland) and } \\
\text { hierarchical multiple } \\
\text { regression } \\
\end{array}$ & $\mathrm{PE}, \mathrm{EE}, \mathrm{SI}$, and $\mathrm{BI}$ & $\begin{array}{c}\mathrm{PE}, \mathrm{EE} \text {, and SI positively affect } \\
\text { BI }\end{array}$ \\
\hline$[33]$ & $\begin{array}{l}\text { Innovation } \\
\text { resistance model }\end{array}$ & $\begin{array}{l}\text { In-vehicle } \\
\text { infotainment } \\
\text { (IVI) systems }\end{array}$ & $\begin{array}{l}\text { Online survey (1070 } \\
\text { samples in Korea) and } \\
\text { PLS-SEM }\end{array}$ & $\begin{array}{l}\text { Technographics, SN, prior } \\
\text { similar experience, PU, } \\
\text { perceived complexity, PR, } \\
\text { resistance, and intention to } \\
\text { use IVI systems }\end{array}$ & $\begin{array}{c}\text { PU negatively affects } \\
\text { resistance, while perceived } \\
\text { complexity and PR positively } \\
\text { affect resistance (which } \\
\text { negatively affects intention to } \\
\text { use) }\end{array}$ \\
\hline$[27]$ & UTAUT & $\begin{array}{l}\text { Self-driving } \\
\text { vehicles }\end{array}$ & $\begin{array}{l}\text { Online survey (556 } \\
\text { residents of Austin, } \\
\text { Texas) and an ordinal } \\
\text { regression model }\end{array}$ & $\begin{array}{l}\text { PE, EE, SI, perceived safety, } \\
\text { anxiety, attitudes about } \\
\text { technology, desire for control, } \\
\text { technology use, technology } \\
\text { acceptance, and intent to use }\end{array}$ & $\begin{array}{l}\text { Intent to use self-driving } \\
\text { vehicles are the ones who } \\
\text { have any physical conditions } \\
\text { that prohibit them from } \\
\text { driving, think it would } \\
\text { decrease accident risk, use } \\
\text { smartphones and } \\
\text { transportation apps, are not } \\
\text { concerned with data privacy, } \\
\text { think it would be fun, think it } \\
\text { would be easy to become } \\
\text { skilful, and believe that people } \\
\text { whose opinions they valued } \\
\text { would like using it }\end{array}$ \\
\hline$[32]$ & $\begin{array}{l}\text { TAM and trust } \\
\text { theory }\end{array}$ & $\begin{array}{l}\text { Autonomous } \\
\text { vehicle }\end{array}$ & $\begin{array}{l}\text { Online survey (552 } \\
\text { drivers) and PLS-SEM }\end{array}$ & $\begin{array}{c}\text { System transparency, } \\
\text { technical competence, } \\
\text { situation management, trust, } \\
\text { PU, PEOU, PR, external locus } \\
\text { of control, sensation seeking, } \\
\text { and BI }\end{array}$ & $\begin{array}{c}\text { System transparency, } \\
\text { technical competence, and } \\
\text { situation management } \\
\text { positively affect trust; PU, } \\
\text { PEOU, trust, and external } \\
\text { locus of control positively } \\
\text { affect intention to use } \\
\text { autonomous vehicles; PR and } \\
\text { sensation have no impact on } \\
\text { BI }\end{array}$ \\
\hline
\end{tabular}

Note: perceived usefulness, PU; perceived ease of use, PEOU; perceived benefit, PB; perceived risks, PR; performance expectancy, PE; effort expectancy, EE; social influence, SI; facilitating conditions, FC; behavioral intention, BI.

the majority of empirical studies attempt to explore the determinants of acceptance using a single theory, such as the technology acceptance model (TAM) [2, 12], the theory of planned behavior (TPB) [14], UTAUT [7, 28, 29, 45], and innovation resistance model [33]. To provide a comprehensive understanding within the adoption decision-making of IoV-based services and vehicles [31], more and more researchers have called for integrating various theories or 
additional factors depending on the certain context to improve the model's explanatory power $[31,46]$, such as the integration of TAM and initial trust theory $[11,15,32,46]$. Therefore, we integrate various theories or constructs widely used and verified in diffident contexts for improving the model's explanatory power.

From a methodology of view, the empirical studies have been grounded mostly in the use of the conventional symmetric-based techniques, including multiple regression model [13, 27-29], SEM [11, 14, 15, 30, 31], and PLS $[10,12,31-35]$, to explore the relationships between variables. However, these techniques focus on the net effect of IV on DV, while excluding possible asymmetric relations between variables [36], leading to the correlation and significance might vary depending on the variables the model includes. For example, most of the empirical previous studies of perceived ease of use, perceived risk, social influence, or facilitating conditions have produced mixed results, and its effect on technology adoption has also been inconsistent. In real-life scenarios, a viable outcome often depends on combinations of several antecedents [37]. To understand the effects of determinants on the intention to accept IoV-based services and vehicles, QCA has been recommended for facilitating the analysis of complex causality and logical relations among combinations of conditions and an outcome $[38,39]$. Therefore, we also answer this call and use fsQCA to provide a more nuanced understanding of how these antecedent conditions fit together to affect consumers' intention to accept and purchase IoVbased services and vehicles.

2.2. Unified Theory of Acceptance and Use of Technology (UTAUT). Information technology (IT) acceptance is an enduring topic in IS research, and a variety of popular models with different sets of acceptance determinant have been developed to explain individual's acceptance and usage of innovation technology, e.g., the theory of reasoned action (TRA) [49], TAM [50], the theory of planned behavior (TPB) [51], task-technology fit (TTF), motivational model, UTAUT [41, 52], initial trust model (ITM) [43], diffusion of innovation theory (IDT) [53], and social cognitive theory. Many studies have used these traditional frameworks or added new constructs to develop models to conduct their research studies in various contexts of technologies.

Considering the choice of theoretical models for explaining user acceptance of new technology, Venkatesh et al. suggested a "need for a review and synthesis to progress toward a unified view of user acceptance" [52]. UTAUT integrating elements across the eight models (i.e., TRA, TAM, motivational model, TPB, a model combining TAM and TPB, the model of PC utilization, IDT, and social cognitive theory) explains more of the variance in user intentions to use new technology than each model [52]. UTAUT2 extends UTAUT with three variables explicitly proposed to be important in the consumer context (i.e., hedonic motivation, price value, and habit). Several studies in the IS discipline have confirmed the explanatory power of UTAUT in the acceptance and adoption studies. Therefore,
UTAUT is considered a robust and powerful model for investigating the determinants of technology adoption at the individual level, and it has generally been applied to understand the individuals' acceptance of various new IT innovations, e.g., IoT in the smart home [54] and mobile learning system [55]. UTAUT is also a commonly employed behavioral model in transport studies from a technology acceptance perspective $[7,35,46]$. Therefore, it is considered theoretically and practically useful to utilize UTAUT2 as an adequate theoretical basis for exploring the effects of factors influencing consumer's acceptance of IoV-based services and vehicles.

\section{Conceptual Model and Hypotheses}

As outlined before, UTAUT2 will be utilized as a foundation to investigate user acceptance of IoV-based services. However, to examine the specific case of IoV-based services acceptance, the model needs to be modified and extended for improving the model's explanatory power and specificity [46]. IoV services, as the emerging technology, include both two-sidedness [26], that is, the technological advantages, and the possible negative consequences of IoV-based services, which should be investigated in parallel. Hence, two perceived factors (initial trust and perceived risk) were incorporated into the original UTAUT2 to form our model because of the uncertainty of the emerging technology. The proposed model is presented in Figure 1. In the following, the constructs of the proposed model and the developed hypotheses will be presented.

3.1. Performance Expectancy. Performance expectancy is defined as the degree to which using technology will provide benefits to consumers in performing certain activities [41]. It is similar to the perceived usefulness of TAM and the relative advantage of IDT [53]. The effect of performance expectancy on behavior intention has been widely verified in previous studies, e.g., mobile learning [56], smart home [57], mobile health [58], and autonomous delivery vehicles [45]. According to IDT [53], users tend to accept new products or innovations if those innovations provide a unique advantage compared to existing ones. Compared with conventional vehicles, IoV-based services have functional benefits such as fewer accidents and reduced fuel consumption and emissions, as well as decreased congestion and driving time $[3,10,48]$. For example, IoV-based services can be synched with traffic signals and other vehicles by capturing the surrounding traffic conditions and environment to decrease travel time and cost [16]. IoV-based services are expected to decrease traveling time through anticipative driving, optimized routing, self-parking systems, and efficient usage of lanes [15]. More specifically, IoV-based services' integrated systems such as real-time navigation aim to provide the driver with a more comfortable and safer driving task [25]. Besides, ubiquitous connectivity allows consumers to be "always connected" or "always on," providing them with more freedom and access to information and services, such as infotainment [33]. Extant studies have shown that 


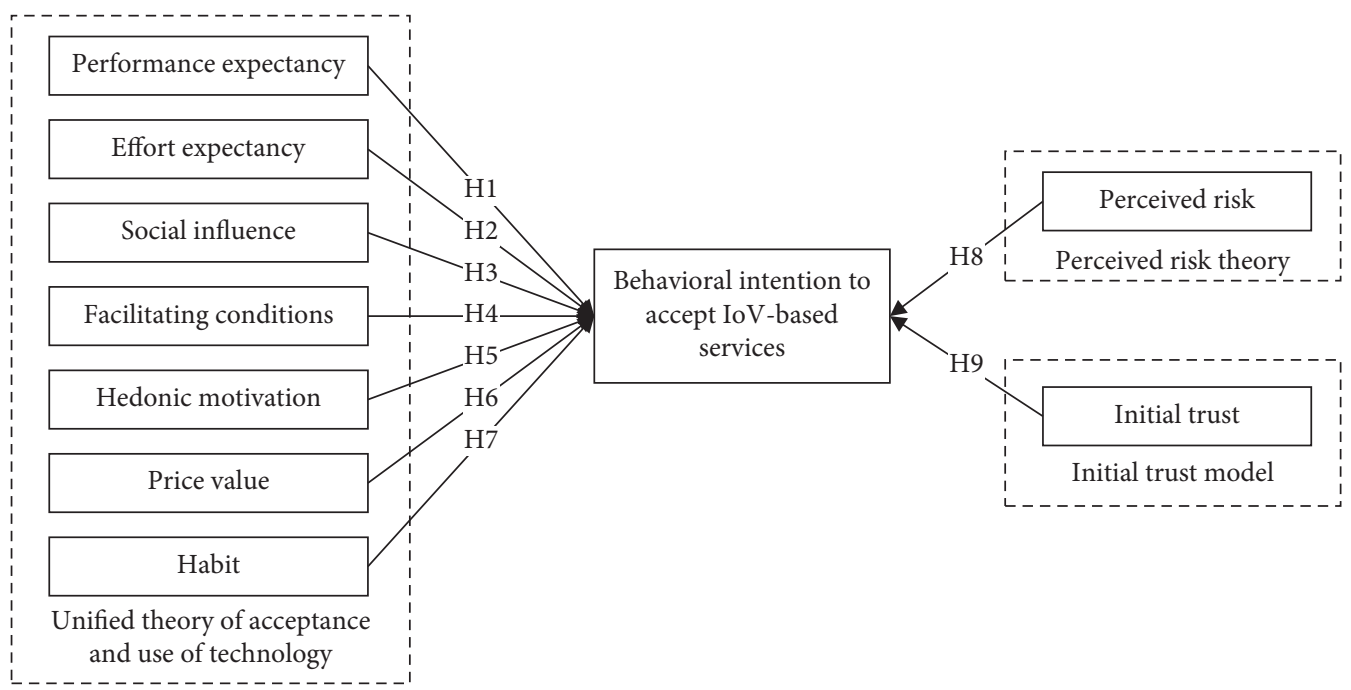

Figure 1: The integrated model of behavioral intention to accept IoV-based services.

technological advantages increase the satisfaction level of consumers and affect the intention of consumers [47]. In this research context, the issue is the extent to which potential consumers will find IoV-based services better than traditional vehicles. Therefore, the more performance expectancy is, the more likely consumers accept IoV-based services.

H1: performance expectancy positively affects IoVbased services' acceptance.

3.2. Effort Expectancy. Effort expectancy is the degree of ease associated with consumers' use of technology [41]. It quite closely with the perceived ease of use of TAM and the complexity of IDT (the degree to which an innovation is perceived as relatively difficult to understand and use) [53]. Even if potential users believe that a given system is useful, meanwhile they may believe that the system is too hard to use and that the benefits of usage are out-weighed by the effort of using the system. Essentially, if IoV-based services were viewed to be difficult to use and complexity would act as a functional barrier, it would harm acceptance [14]. Effort expectancy has also been proven to be relevant with intention in various contexts, e.g., mobile learning [56]. Unlike conventional vehicles, IoV-based services do not require the driver to monitor and take back the operational control of the vehicle even when the system becomes failure [10]. Moreover, with the effortless communication with the human-car interaction system [35], the drivers just need to issue the instructions and confirm to IoV-based services, especially when they have a special preference or instant requirement. Analogously, we pose the following hypothesis.

$\mathrm{H} 2$ : perceived ease of use positively affects IoV-based services' acceptance.

3.3. Social Influence. Social influence is defined as consumers perceive that important others (e.g., family and friends) believe they should use the new technology [41, 52], reflecting the effect of social environmental factors such as the opinions of a user's surrounding friends, relatives, and superiors on user behavior, which is similar to the subjective norm of TRA $[48,49]$. Previous studies also reveal the impacts of social influence on behavioral intention in various contexts, e.g., mobile payment [59], mobile banking [60], mobile learning [56], IoT in smart home [54], wearable technology [61], and autonomous delivery vehicles [45]. As a person in society [14], an individual's decision of technology adoption is very susceptible to their social networks [31] and social norms $[35,62]$. For IoV-based services, such a disruptive innovation in a burgeoning market, Talebian and Mishra [16] find that peer-to-peer communication (wordof-mouth) with a satisfied adopter from the social circles can not only convince a potential adopter that the resistances which he/she perceives are perhaps not important but also it is worthwhile to purchase IoV-based services. Besides, the use of autonomous vehicles by friends and family leads to a greater willingness to adopt the technology [63]. When friends, family, or other important ones start to use IoVbased services, consumers would be more likely to pay for an IoV-based service or vehicle [7].

H3: social influence positively affects behavioral intention to accept IoV-based services.

3.4. Facilitating Conditions. Facilitating conditions are defined as a user's perception of disposable resources and support when performing a behavior $[41,52]$, which are similar to perceived behavioral control of TPB [51]. It is significant in various technologies acceptance studies, e.g., mobile banking $[60,64]$ and automated public transport [29]. IoV-based service/vehicle as new technology requires users to have certain skills such as configuring and operating smart applications to connect to the wireless Internet. It is believed that users have different levels in possessing information and resources that facilitate their use of IoV-based services (e.g., personal knowledge and help-hotlines). In 
general, consumers with a lower level of facilitating conditions will have lower intentions to accept or purchase IoVbased services [45].

H4: facilitating conditions positively affects behavioral intention to accept IoV-based services.

3.5. Hedonic Motivation. Hedonic motivation, considered as an intrinsic value, refers to the fun or pleasure derived from using a technology [41]. In IS adoption research, such hedonic motivation conceptualized as perceived enjoyment and has been found to play an important role in the acceptance and usage of various technologies, e.g., smart home [57], mobile health [58], and autonomous delivery vehicles [45]. The proposed system or technology must arouse the user's emotions and make the experience enjoyable and positive to motivate users to adopt it [57]. In the IoV context, hedonic motivation has also been found to be an important determinant of acceptance and purchase of autonomous shuttle services $[29,45,46]$. The attractiveness of new IoVbased services can be increased by the enjoyment experience provided by technology [46].

H5: hedonic motivation positively affects behavioral intention to accept IoV-based services.

3.6. Price Value. Price value is defined as the consumers' cognitive tradeoff between a technology's perceived benefits and its monetary costs of usage [41]. In marketing research, the perception of price/cost is usually conceptualized together with the quality to determine the perceived value of products or services, reflecting the influence of the individually perceived price-performance and personal financial aspects. A positive price value occurs if the potential consumers' perceived benefits of using technology are greater than the associated monetary costs, which has a positive impact on consumers' adoption and usage of new technology [48]. Price value is a significant determinant of behavioral intention in various contexts, e.g., smart home [54]. Price value is expected to be particularly influential on IoV-based services acceptance as IoV technologies are evaluated against their comparable non-IoV objects. Although some studies have indicated that potential consumers are generally willing to pay a higher price for autonomous vehicles than conventional ones [63], however, they need to tradeoff price value when purchasing such a disruptive product $[48,65,66]$.

H6: price value positively affects behavioral intention to accept IoV-based services.

3.7. Habit. Habit is defined as the extent to which people tend to perform behaviors automatically as they learn how to use a new technology [41]. It usually reflects the consequences and results of prior experiences with a target technology [57]. That is when behavior is repeated, a habit is developed. Accordingly, the behavior is likely to be determined by habit strength [67]. The habit has been shown to have a direct effect on technology use, e.g., smart home [57].
Therefore, the greater the habit of consumers to use the IoVbased services, the greater will be their intentions to adopt.

H7: habit positively affects behavioral intention to accept IoV-based services.

3.8. Perceived Risk. Perceived risk relates to the uncertainty regarding the occurrence of adverse consequences $[16,68,69]$. It is defined as the degree to which consumers feel uncertainty and problems about the possibility of negative consequences from accepting a technology and drawing from perceived risk theory [42]. Consumers often weigh benefits and risks beliefs about technology through cognitive processes that inform their decisions to accept or reject it [34]. Numerous studies use perceived risk in analyzing consumer behavior related to innovative technology and find it is negatively related to intention to use such innovative technology as IoT [70], smart home services [68], e-government [71, 72], social commerce [73], Internet banking [74-76], mobile payment [77], particularly automated vehicles [11,47], and autonomous delivery vehicles [45]. Dialectically, everything has two sides. Many surveys have reported that while consumers acknowledge the potential benefits of IoV-based services, they have also expressed great concerns about safety and privacy risks associated with the acceptance of IoV-based services $[3,6]$. Safety risk includes the malfunctioning risk due to operating system/equipment failure/crash, virus attack, or disconnection from the Internet [16], as well as vehicle performance degradation when operating in such complex conditions as poor weather, night, limited visibility, and in areas with low Internet coverage [3]. Privacy risk originates from the possibility that travel data, behavioral data, or personal information could be transmitted to other organizations for misuse without notice or be hacked by others $[11,48]$. Previous studies show that users seem to have privacy concerns when being confronted with the concept of connected vehicles because users of connected vehicular services may be concerned with the service providers' handling of data in terms of information collection, storage, and usage [35]. Such risks are considered as the most important barriers for acceptance of IoV-based services $[10,16]$. Therefore, the more perceived risk consumers assess, the less consumers are willing to accept IoV-based services.

H8: perceived risk negatively affects behavioral intention to accept IoV-based services.

3.9. Initial Trust. Initial trust refers to the trustor's subjective knowledge and confidence of trustee without experience and knowledge $[35,43]$. In technology adoption research, trust is the expectation of adopter toward the adoptee to satisfy a certain service or fulfill a certain promise. Under risky or uncertain situations, trust is treated as a vital component of a relationship [8,78]. Numerous studies have extensively explored trust as an important determinant to affect user acceptance of various technology services, e.g., mobile banking [64, 79], e-government [71], IoT in agriculture [70], 
particularly autonomous vehicles [11, 32], and autonomous shuttle $[46,48]$. An individual tends to accept an innovation only if they believe that the specific attributes of this innovation will help achieve one's goals [80]. If trust is absent, even individual who tends to make adoption decision may start to defer adoption or hold a wait-and-see attitude until the market of radical innovation (IoV-based services) matures. At the early stage of the marketization of IoV-based services and vehicles, potential consumers need to shape sufficient trust that can help to increase the expectation of successful application of relevant IoV-based services, overcome perceptions of risks and uncertainties, and form a positive attitude towards it $[11,43]$.

H9: initial trust positively affects behavioral intention to accept IoV-based services.

\section{Methodology}

4.1. Measurements. A survey questionnaire was conducted to collect data for this study. Based on an extensive review of the literature, each construct and its items were adapted from validated instruments of previous studies, and wording was modified to fit the context of IoV-based services and vehicles [72], to improve content validity [50, 81]. The method of translation and back translation was used for ensuring equivalence between the source and translated versions [82]. Appropriate modifications were made based on expert reviews by two IS experts. Several postgraduate students pretested the instrument, identifying and revising ambiguous or poorly worded items to improve the clarity and understandability. The instrument was then pilot tested with 30 undergraduate students who were not included in the main survey. The results of pilot test confirmed the reliability, validity, and translational equivalence of the scales. The final items and their sources are listed in Table 2. All items were measured using a five-point Likert scale ranging from "strongly disagree" to "strongly agree."

4.2. Data Collection. The data were collected through an online survey by Wenjuanxing (http://www.wenjuan.com), a professional online questionnaire survey platform in China, from 22 to 26 June 2020. The survey targeted consumers who are using or intend to use an IoV-based service and vehicle. The survey includes a short explanation of the definition and functions of IoV-based services to help respondents understand this concept. The questionnaire was distributed randomly to actual respondents by Wenjuanxing. A total of 420 questionnaires were collected. Excluding invalid questionnaires with unusually short completion time, incomplete data, or the same options, there were 362 valid questionnaires for this study. The demographic characteristics and driving-related information of the respondents are shown in Table 3.

As seen in Table 3, the demographic data indicate that the sample was balanced regarding gender $(51.38 \%$ of the respondents are male) and age (51.66\% of the respondents are less than 30 years old), consisting primarily of bachelor degree and above (93.37\%).
Nonresponse bias generally occurs when some of the target individuals are unwilling or unable to participate in the survey and, consequently, causes an unreliable representation of the selected sample and limit a study's external validity [84]. Following the recommendations of Urbach and Frederik [85], we took measures to address the issue of nonresponse and make sure we had a representative response rate, both before, during, and after data collection [86]. To minimize nonresponse before and during the data collection, all respondents were provided with a monetary incentive to participate in the questionnaire. Besides, following the initial invitation to participate in the questionnaire, all of the respondents were recontacted to remind them to complete the survey. After the data collection, nonresponse bias was assessed by verifying that the responses of early and late respondents were not significantly different $[84,87]$. In both samples, the early and late responses had insignificant differences in the means of any demographics based on T-tests using SPSS. Therefore, nonresponse bias is not a major concern in this study.

Taking into consideration that all data were collected from a single source at one point in time and that all data were perceptions of key respondents, we used two approaches, i.e., Harman's one-factor test [88] and full collinearity assessment approach [89], to test the existence of common method bias (CMB), based on the guidelines of previous studies [44, 54, 90]. First, Harman's single-factor test shows that the highest variance explained by the single factor is $44.95 \%$, which is less than the threshold value of $50 \%$, indicating the absence of CMB in the dataset. Second, $\mathrm{CMB}$ is examined through a full collinearity assessment approach in PLS-SEM [89]. The variance inflation factor (VIF) values of all the latent variables are less than 4.58 (see Table 4), which is below the acceptable threshold of 5. Taken together, these results indicated that $\mathrm{CMB}$ was minimal in this study.

\section{Data Analysis and Results}

Data were analyzed using both the PLS-SEM method with Smart PLS 3 for validating the measurement model and structural model [81], and the fsQCA 3.0 software for exploring the set relations of the casual and outcome conditions [38]. These two methods have different focuses and rely on different principles [91]. The PLS-SEM is a variableoriented technique that focuses on the net effect of the independent variable (IV) on the dependent variable (DV). It treats independent variables as competing to explain the variation in the dependent variables, and it relies on the principles of additive effects, linearity, and unifinality [40]. On the contrary, the fsQCA is a case-oriented technique that focuses on combinatorial effects. It assumes complex causality and focuses on asymmetric relationships between conditions (IV) and outcome (DV) [91]. FsQCA also allows for multifinality in which identical conditions can lead to different outcomes [39]. Thus, fsQCA is considered as an appropriate complementary analysis to PLS-SEM when detecting effects caused by unobserved heterogeneity [40, 92-94]. 
TABLe 2: Measurement scale and items.

\begin{tabular}{|c|c|c|c|}
\hline Constructs & No. & Items & References \\
\hline Perceived expectancy & $\begin{array}{l}\text { PE1 } \\
\text { PE2 } \\
\text { PE3 } \\
\text { PE4 }\end{array}$ & $\begin{array}{l}\text { Using IoV services will improve driving and travel performance } \\
\text { Using IoV services will increase driving and travel effectiveness } \\
\text { Using IoV services will enhance my effectiveness while driving } \\
\text { I find IoV services are useful }\end{array}$ & {$[41]$} \\
\hline Effort expectancy & $\begin{array}{l}\text { EE1 } \\
\text { EE2 } \\
\text { EE3 }\end{array}$ & $\begin{array}{l}\text { Learning how to use IoV services is easy for me } \\
\text { I would find it easy to get IoV services to do what I want to do } \\
\text { Interacting with IoV services would not require a lot of my mental effort }\end{array}$ & \\
\hline Social influence & $\begin{array}{l}\text { SI1 } \\
\text { SI2 } \\
\text { SI3 }\end{array}$ & $\begin{array}{l}\text { People who are important to me think that I should use IoV services } \\
\text { People who influence my behavior think that I should use IoV services } \\
\text { People whose opinions that I value prefer that I use IoV services }\end{array}$ & \\
\hline Facilitating conditions & $\begin{array}{l}\text { FC1 } \\
\text { FC2 } \\
\text { FC3 } \\
\text { FC3 }\end{array}$ & $\begin{array}{l}\text { I have the resources necessary to use IoV services } \\
\text { I have the knowledge necessary to use IoV services } \\
\text { IoV services are compatible with other technologies I use } \\
\text { I can get help from others when I have difficulties using IoV services }\end{array}$ & \\
\hline Hedonic motivation & $\begin{array}{l}\text { HM1 } \\
\text { HM2 } \\
\text { HM3 }\end{array}$ & $\begin{array}{c}\text { Using IoV services is fun } \\
\text { Using IoV services is enjoyable } \\
\text { Using IoV services is very entertaining }\end{array}$ & \\
\hline Price value & $\begin{array}{l}\text { PV1 } \\
\text { PV2 } \\
\text { PV3 }\end{array}$ & $\begin{array}{l}\text { IoV service is reasonably priced } \\
\text { IoV service is a good value for the money } \\
\text { At the current price, the IoV service provides a good value }\end{array}$ & \\
\hline Habit & $\begin{array}{l}\text { HA1 } \\
\text { HA2 } \\
\text { HA3 }\end{array}$ & $\begin{array}{c}\text { The use of IoV services has become a habit for me } \\
\text { I am addicted to using IoV services } \\
\text { I must use IoV services }\end{array}$ & {$[41,57]$} \\
\hline Perceived risk & $\begin{array}{l}\text { PR1 } \\
\text { PR2 } \\
\text { PR3 } \\
\text { PR4 }\end{array}$ & $\begin{array}{l}\text { I'm worried about the general safety of IoV services } \\
\text { I'm worried about the failure or malfunctions of IoV services which may cause } \\
\text { accidents } \\
\text { I am concerned IoV services will collect too much personal information from me } \\
\text { I am concerned IoV services will use my personal information for other purposes } \\
\text { without my authorization } \\
\text { I am concerned IoV services will share my personal information with other entities } \\
\text { without my authorization }\end{array}$ & [8] \\
\hline Initial trust & $\begin{array}{l}\text { TR1 } \\
\text { TR2 } \\
\text { TR3 }\end{array}$ & $\begin{array}{l}\text { IoV service is dependable } \\
\text { IoV service is reliable } \\
\text { Overall, I can trust IoV services }\end{array}$ & {$[11]$} \\
\hline $\begin{array}{l}\text { Behavioral intention to accept } \\
\text { IoV services }\end{array}$ & $\begin{array}{l}\mathrm{BI} 1 \\
\mathrm{BI} 2 \\
\mathrm{BI} 3\end{array}$ & $\begin{array}{l}\text { Given the chance, I intend to use IoV services } \\
\text { Given the chance, I predict that I should use IoV services in the future } \\
\text { I likely have the intention to use IoV services to conduct driving }\end{array}$ & {$[83]$} \\
\hline
\end{tabular}

5.1. PLS-SEM Analysis. The variance-based PLS-SEM method, a symmetric approach for modeling, is widely used in various studies $[90,95]$. PLS-SEM enables to estimate the complex models with many constructs, indicator variables, and structural paths without imposing distributional assumptions on the data, which is often recommended when the focus of research is prediction rather than hypothesis testing when the sample size is not large, or in the presence of noisy data [81, 95]. Following the two-step approach recommended by Zhou [79], the measurement model was used to assess reliability and validity, and the structural model was examined to test hypotheses and model fitness.

5.1.1. Measurement Model. A measurement model was used to assess the reliability and validity [81]. The internal consistency reliability of the scales was measured by Cronbach's alpha (CA) and composite reliability (CR) [96]. Table 4 shows that $\mathrm{CA}$ and $\mathrm{CR}$ of all constructs are more than
0.7 , thus confirming the excellent reliability of scale [97]. The indicator reliability was evaluated based on the criterion that the loadings should be greater than 0.70. As shown in Table 4, the loadings (in bold) are greater than 0.708 [81], meaning that the instrument presents good indicator reliability.

Construct validity includes two fundamental aspects, i.e., convergent validity and discriminant validity [97]. Convergent validity, the extent to which the construct converges to explain the variance of its items, is determined by average variance extracted (AVE) [96]. Table 4 shows that AVE is greater than 0.5 for all of the constructs, meaning that the instrument presents good convergent validity [81].

Discriminant validity is the extent to which a construct is empirically distinct from other constructs in the structural model. The discriminant validity of the constructs is examined by using two criteria, i.e., the Fornelle-Larcker criterion and cross-loadings' criterion. Fornell-Larcker criterion requires that the square root of AVE be higher than 
TABLE 3: Demographic characteristics and driving-related information.

\begin{tabular}{|c|c|c|c|}
\hline Variables & Items & Frequency & Percentage \\
\hline \multirow{2}{*}{ Gender } & Male & 186 & 51.38 \\
\hline & Female & 176 & 48.62 \\
\hline \multirow{5}{*}{ Age } & $18 \sim 25$ & 121 & 33.43 \\
\hline & $26 \sim 30$ & 66 & 18.23 \\
\hline & $31 \sim 40$ & 131 & 36.19 \\
\hline & $41 \sim 50$ & 32 & 8.84 \\
\hline & More than 51 & 12 & 3.31 \\
\hline \multirow{5}{*}{ Education } & High school or less & 8 & 2.21 \\
\hline & Junior college & 16 & 4.42 \\
\hline & Bachelor degree & 135 & 37.29 \\
\hline & Master degree & 117 & 32.32 \\
\hline & Ph. D. and above & 86 & 23.76 \\
\hline \multirow{11}{*}{ Occupation } & Senior manager & 55 & 15.19 \\
\hline & Professionals & 93 & 25.69 \\
\hline & Civil servant & 3 & 0.83 \\
\hline & Company employee & 50 & 13.81 \\
\hline & Service worker & 3 & 0.83 \\
\hline & Labor & 2 & 0.55 \\
\hline & Private entrepreneurs & 8 & 2.21 \\
\hline & Self-employer & 10 & 2.76 \\
\hline & Student & 118 & 32.60 \\
\hline & Unemployed & 7 & 1.93 \\
\hline & Other & 13 & 3.59 \\
\hline \multirow{7}{*}{ Monthly household income ( $¥)$} & Less than 3001 & 22 & 6.08 \\
\hline & $3001-5000$ & 45 & 12.43 \\
\hline & $5001-10,000$ & 111 & 30.66 \\
\hline & $10,001-15,000$ & 80 & 22.10 \\
\hline & $15,001-20,000$ & 47 & 12.98 \\
\hline & $20,001-30,000$ & 34 & 9.39 \\
\hline & More than 30,000 & 23 & 6.35 \\
\hline \multirow{2}{*}{ Driver's license } & Yes & 318 & 87.85 \\
\hline & No & 44 & 12.15 \\
\hline \multirow{2}{*}{ Car purchase experience } & Yes & 193 & 53.31 \\
\hline & No & 169 & 46.69 \\
\hline \multirow{5}{*}{ Number of cars owned by the household } & 0 & 54 & 14.92 \\
\hline & 1 & 206 & 56.91 \\
\hline & 2 & 91 & 25.14 \\
\hline & 3 & 8 & 2.21 \\
\hline & $>3$ & 3 & 0.83 \\
\hline \multirow{9}{*}{ IoV-based services most frequently used } & Automatic parking assist & 56 & 15.47 \\
\hline & Adaptive cruise control & 73 & 20.17 \\
\hline & Collision avoidance system & 51 & 14.09 \\
\hline & In-vehicle infotainment & 81 & 22.38 \\
\hline & Human-machine interaction & 168 & 46.41 \\
\hline & Intelligent navigation & 109 & 30.11 \\
\hline & Unconscious pay & 198 & 54.70 \\
\hline & Self-driving & 9 & 2.49 \\
\hline & Other & 79 & 21.82 \\
\hline
\end{tabular}

the correlations between the constructs [96], and the crossloadings' criterion requires that the factor loading must be higher than all cross loadings [98]. As seen in Tables 5 and 6, both criteria satisfy the discriminant validity of the constructs.

5.1.2. Structural Model. Before assessing the structural model, collinearity must be tested to make sure it does not bias the regression results [81]. The variance inflation factors
(VIF) (often used to evaluate collinearity) are between 1 and 4.1, which are less than the threshold of 5 [81]. This indicates that there is no concern about the collinearity issue. The path coefficients $(\beta)$, Cronbach's alpha, and $R^{2}$ values were assessed through the PLS Algorithm (essentially a sequence of regressions in terms of weight vectors) and Bootstrapping (a nonparametric procedure that allows testing the statistical significance of various PLS-SEM results) with 5000 iterations of resampling [97]. The results are shown in Figure 2. 
TABLE 4: CA, CR, AVE, and VIF of the constructs.

\begin{tabular}{lllll}
\hline & CA & CR & AVE & VIF \\
\hline PE & 0.91 & 0.94 & 0.78 & 4.39 \\
EE & 0.96 & 0.97 & 0.92 & 3.92 \\
SI & 0.93 & 0.96 & 0.88 & 4.24 \\
FC & 0.89 & 0.93 & 0.76 & 4.58 \\
HM & 0.94 & 0.96 & 0.89 & 4.17 \\
PV & 0.93 & 0.96 & 0.88 & 2.76 \\
HA & 0.93 & 0.95 & 0.87 & 2.76 \\
PR & 0.91 & 0.93 & 0.73 & 1.20 \\
TR & 0.96 & 0.97 & 0.93 & 4.14 \\
UI & 0.94 & 0.96 & 0.89 & - \\
\hline
\end{tabular}

Note: perceived expectancy, PE; effort expectancy, EE; social influence, SI; facilitating conditions, FC; hedonic motivation, HM; price value, PV; habit, HA; perceived risk, PR; initial trust, TR; behavioral intention of IoV-based services, BI.

TABLE 5: Loadings and cross-loadings.

\begin{tabular}{|c|c|c|c|c|c|c|c|c|c|c|}
\hline & $\mathrm{PE}$ & $\mathrm{EE}$ & SI & $\mathrm{FC}$ & $\mathrm{HM}$ & $\mathrm{PV}$ & HA & $\mathrm{PR}$ & TR & $\mathrm{BI}$ \\
\hline PE1 & 0.92 & 0.72 & 0.73 & 0.71 & 0.75 & 0.56 & 0.59 & -0.26 & 0.68 & 0.69 \\
\hline PE2 & 0.85 & 0.61 & 0.70 & 0.61 & 0.67 & 0.49 & 0.51 & -0.28 & 0.59 & 0.57 \\
\hline PE3 & 0.92 & 0.76 & 0.78 & 0.73 & 0.80 & 0.62 & 0.62 & -0.28 & 0.72 & 0.73 \\
\hline PE4 & 0.86 & 0.73 & 0.67 & 0.67 & 0.70 & 0.46 & 0.50 & -0.32 & 0.64 & 0.63 \\
\hline EE1 & 0.75 & 0.96 & 0.70 & 0.75 & 0.72 & 0.55 & 0.58 & -0.31 & 0.62 & 0.67 \\
\hline EE2 & 0.77 & 0.97 & 0.73 & 0.79 & 0.75 & 0.57 & 0.60 & -0.29 & 0.65 & 0.69 \\
\hline EE3 & 0.78 & 0.96 & 0.77 & 0.80 & 0.78 & 0.59 & 0.60 & -0.33 & 0.69 & 0.70 \\
\hline SI1 & 0.79 & 0.75 & 0.94 & 0.75 & 0.80 & 0.60 & 0.59 & -0.33 & 0.73 & 0.68 \\
\hline SI2 & 0.75 & 0.72 & 0.95 & 0.72 & 0.79 & 0.63 & 0.62 & -0.36 & 0.70 & 0.68 \\
\hline SI3 & 0.75 & 0.69 & 0.93 & 0.73 & 0.74 & 0.62 & 0.58 & -0.36 & 0.66 & 0.68 \\
\hline FC1 & 0.58 & 0.61 & 0.67 & 0.84 & 0.66 & 0.53 & 0.55 & -0.25 & 0.63 & 0.57 \\
\hline FC2 & 0.68 & 0.74 & 0.67 & 0.88 & 0.70 & 0.53 & 0.54 & -0.25 & 0.61 & 0.62 \\
\hline FC3 & 0.74 & 0.76 & 0.68 & 0.90 & 0.78 & 0.55 & 0.60 & -0.25 & 0.67 & 0.68 \\
\hline FC4 & 0.67 & 0.72 & 0.71 & 0.86 & 0.76 & 0.61 & 0.59 & -0.27 & 0.68 & 0.65 \\
\hline HM1 & 0.80 & 0.77 & 0.79 & 0.81 & 0.95 & 0.63 & 0.64 & -0.35 & 0.77 & 0.73 \\
\hline HM2 & 0.78 & 0.73 & 0.78 & 0.80 & 0.95 & 0.61 & 0.62 & -0.33 & 0.78 & 0.71 \\
\hline HM3 & 0.77 & 0.70 & 0.76 & 0.76 & 0.93 & 0.66 & 0.66 & -0.33 & 0.86 & 0.76 \\
\hline PV1 & 0.54 & 0.55 & 0.61 & 0.60 & 0.61 & 0.93 & 0.68 & -0.29 & 0.61 & 0.67 \\
\hline PV2 & 0.58 & 0.58 & 0.62 & 0.61 & 0.64 & 0.95 & 0.72 & -0.26 & 0.66 & 0.73 \\
\hline PV3 & 0.58 & 0.55 & 0.62 & 0.59 & 0.64 & 0.94 & 0.72 & -0.29 & 0.63 & 0.70 \\
\hline HA1 & 0.62 & 0.61 & 0.62 & 0.65 & 0.67 & 0.74 & 0.95 & -0.29 & 0.65 & 0.76 \\
\hline HA2 & 0.51 & 0.50 & 0.53 & 0.53 & 0.56 & 0.64 & 0.91 & -0.29 & 0.56 & 0.67 \\
\hline HA3 & 0.62 & 0.61 & 0.63 & 0.66 & 0.66 & 0.72 & 0.95 & -0.28 & 0.65 & 0.79 \\
\hline PR1 & -0.27 & -0.26 & -0.31 & -0.23 & -0.31 & -0.17 & -0.21 & 0.88 & -0.21 & -0.25 \\
\hline PR2 & -0.29 & -0.31 & -0.33 & -0.29 & -0.35 & -0.23 & -0.23 & 0.90 & -0.26 & -0.27 \\
\hline PR3 & -0.27 & -0.29 & -0.34 & -0.24 & -0.31 & -0.18 & -0.21 & 0.90 & -0.24 & -0.26 \\
\hline PR4 & -0.29 & -0.28 & -0.30 & -0.25 & -0.29 & -0.28 & -0.31 & 0.86 & -0.23 & -0.29 \\
\hline PR5 & -0.25 & -0.24 & -0.31 & -0.24 & -0.28 & -0.40 & -0.34 & 0.75 & -0.27 & -0.28 \\
\hline TR1 & 0.73 & 0.66 & 0.72 & 0.72 & 0.83 & 0.64 & 0.64 & -0.29 & 0.97 & 0.75 \\
\hline TR2 & 0.70 & 0.62 & 0.68 & 0.70 & 0.80 & 0.64 & 0.62 & -0.24 & 0.96 & 0.71 \\
\hline TR3 & 0.73 & 0.68 & 0.73 & 0.72 & 0.84 & 0.66 & 0.66 & -0.30 & 0.95 & 0.77 \\
\hline BI1 & 0.69 & 0.64 & 0.69 & 0.67 & 0.73 & 0.68 & 0.72 & -0.30 & 0.74 & 0.93 \\
\hline BI2 & 0.71 & 0.68 & 0.67 & 0.69 & 0.73 & 0.69 & 0.76 & -0.30 & 0.72 & 0.95 \\
\hline BI3 & 0.71 & 0.70 & 0.69 & 0.70 & 0.75 & 0.74 & 0.77 & -0.30 & 0.74 & 0.96 \\
\hline
\end{tabular}

Note: the characters in bold are the indicator loadings of the constructs.

Figure 2 indicate that performance expectancy $(\beta=0.15$, $p<0.05)$, price value $(\beta=0.153, p<0.01)$, habit $(\beta=0.34$, $p<0.001)$, and initial trust $(\beta=0.218, p<0.001)$ are statistically significant to explain the intention to accept IoVbased services. Thus, hypotheses $\mathrm{H} 1, \mathrm{H} 6, \mathrm{H} 7$, and $\mathrm{H} 9$ are supported, whereas effort expectancy $(\beta=0.106, p=0.068)$, social influence $(\beta=-0.01, p=0.888)$, facilitating conditions $(\beta=-0.003, \quad p=0.964)$, hedonic motivation $(\beta=0.059$, $p=0.459)$, and perceived risk $(\beta=-0.008, p=0.771)$ have no statistically significant effect. Thus, hypotheses $\mathrm{H} 2, \mathrm{H} 3$, $\mathrm{H} 4, \mathrm{H} 5$, and $\mathrm{H} 8$ are not confirmed. In sum, the model can explain the variance of $78 \%\left(R^{2}\right)$ in behavioral intention to accept IoV services, indicating the model's substantial explanatory power [81]. 
TABLE 6: Discriminant validity of the constructs.

\begin{tabular}{|c|c|c|c|c|c|c|c|c|c|c|}
\hline & $\mathrm{PE}$ & $\mathrm{EE}$ & SI & FC & HM & PV & HA & PR & TR & $\mathrm{BI}$ \\
\hline $\mathrm{PE}$ & 0.89 & & & & & & & & & \\
\hline $\mathrm{EE}$ & 0.80 & 0.96 & & & & & & & & \\
\hline SI & 0.81 & 0.77 & 0.94 & & & & & & & \\
\hline FC & 0.77 & 0.82 & 0.78 & 0.87 & & & & & & \\
\hline HM & 0.83 & 0.78 & 0.83 & 0.84 & 0.94 & & & & & \\
\hline PV & 0.61 & 0.59 & 0.66 & 0.64 & 0.67 & 0.94 & & & & \\
\hline HA & 0.63 & 0.62 & 0.64 & 0.66 & 0.68 & 0.75 & 0.93 & & & \\
\hline PR & -0.32 & -0.32 & -0.37 & -0.29 & -0.36 & -0.30 & -0.31 & 0.86 & & \\
\hline TR & 0.75 & 0.68 & 0.74 & 0.74 & 0.86 & 0.68 & 0.67 & -0.29 & 0.96 & \\
\hline BI & 0.74 & 0.71 & 0.72 & 0.73 & 0.78 & 0.74 & 0.79 & -0.32 & 0.78 & 0.95 \\
\hline
\end{tabular}

Note: the diagonal in bold is the square root of the average variance extracted (AVE).

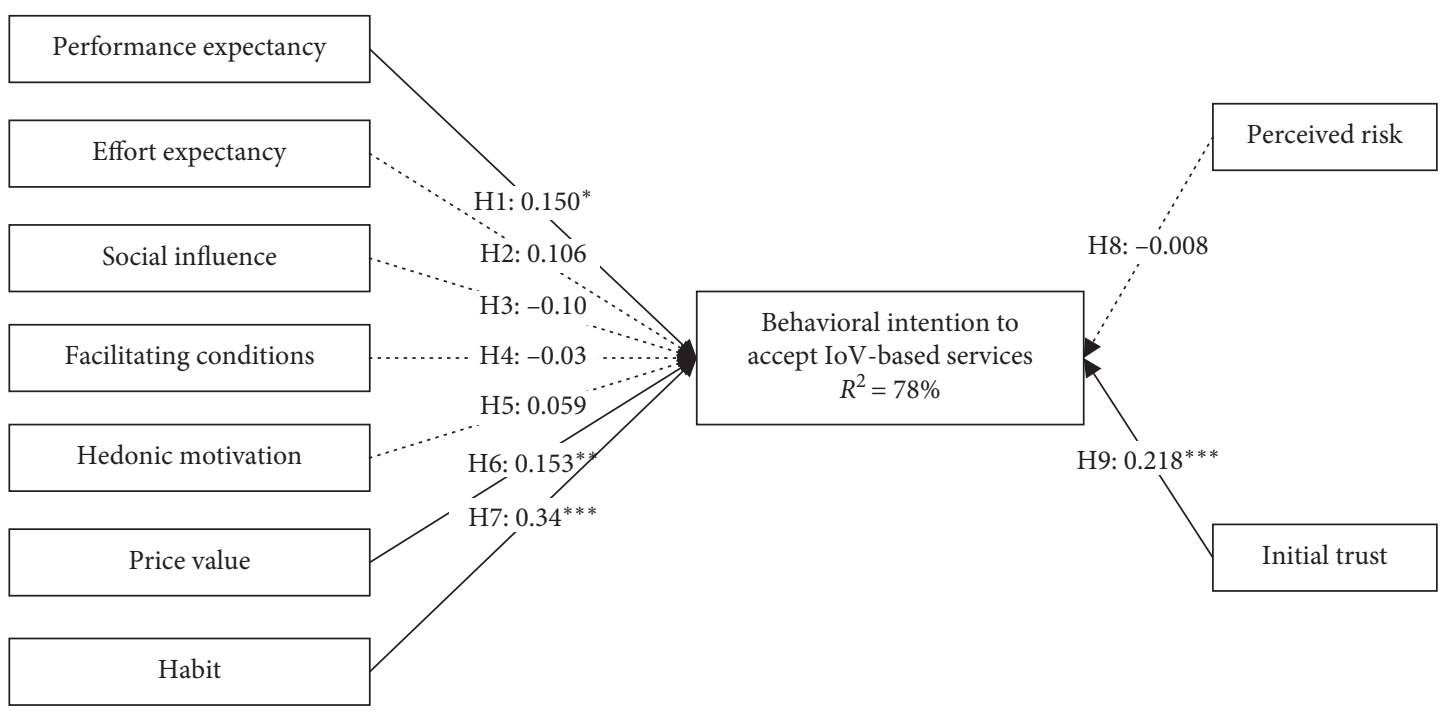

Figure 2: The results of structural model of IoV-based services' acceptance. Note: ${ }^{*} p<0.05 ;{ }^{* *} p<0.01$; and ${ }^{* * *} p<0.001$.

5.2. Qualitative Comparative Analysis. FsQCA provides suitable methods to accommodate complex complementarities and nonlinear relationships among constructs [37]. FsQCA has attracted the attention of researchers in several fields, e.g., strategy and organization research $[99,100]$ and information management [94, 101]. Therefore, this study employs fsQCA for a detailed analysis of how causal conditions contribute to an outcome $[39,100]$. The key stages of a fsQCA study contain model building, sampling, calibration, data analysis, reporting, and interpretation of findings [99]. Before analysis, data should be calibrated first from the original five-point Likert scale into a dataset suitable for data analysis by fsQCA.

5.2.1. Calibration. A five-point Likert scale provides information to calibrate these variables; however, the actual sample is not normally distributed [92]. Therefore, the mean of each variable was chosen as the crossover point [100], rather than the median of a five-point Likert scale [58]. Using the fsQCA 3.0 Software, calibration is automated completed and shown as Table 7.
5.2.2. Analysis of Necessary Conditions. This study begins with the analysis of necessary conditions $[91,102]$. An analysis of necessary conditions determines whether any causal condition can be regarded as a necessary condition for the outcome to occur [103]. Drawing upon the recommendations $[44,58,99,103]$, a condition is necessary when its consistency score is greater than the threshold of 0.9 . Table 8 presents the results of the analysis of necessary conditions considering both the presence and the absence $(\sim)$ of the conditions for two outcome variables, i.e., behavioral intention to accept IoV services ("BI") and the negation of behavioral intention to accept IoV services (" $\sim \mathrm{BI}$ ”). The results show that none of the conditions alone, except PE (consistency is 0.932) and EE (consistency is 0.931 ), is necessary conditions for the outcome "BI." Besides, none of the conditions alone is a necessary condition for the outcome " $\sim \mathrm{BI}$," except " HA."

5.2.3. Analysis of Sufficient Conditions for Behavioral Intention to Accept IoV Services. To explore which conditions might consistently result in the intention to accept IoV-based services, the truth table algorithm described by 
TABLE 7: Full membership, full nonmembership, and a crossover point of calibration.

\begin{tabular}{lccc}
\hline & $\begin{array}{c}\text { Full } \\
\text { nonmembership }\end{array}$ & $\begin{array}{c}\text { Crossover } \\
\text { point }\end{array}$ & $\begin{array}{c}\text { Full } \\
\text { membership }\end{array}$ \\
\hline $\begin{array}{l}\text { Perceived } \\
\text { expectancy }\end{array}$ & 1 & 3.9 & 5 \\
$\begin{array}{l}\text { Effort } \\
\text { expectancy }\end{array}$ & 1 & 3.9 & 5 \\
$\begin{array}{l}\text { Social influence } \\
\text { Facilitating }\end{array}$ & 1 & 3.9 & 5 \\
$\begin{array}{l}\text { conditions } \\
\text { Hedonic }\end{array}$ & 1 & 3.9 & 5 \\
motivation & 1 & 3.9 & 5 \\
$\begin{array}{l}\text { Price value } \\
\text { Habit }\end{array}$ & 1 & 3.9 & 5 \\
$\begin{array}{l}\text { Perceived risk } \\
\text { Initial trust }\end{array}$ & 1 & 3.9 & 5 \\
$\begin{array}{l}\text { Behavioral } \\
\text { intention }\end{array}$ & 1 & 2.3 & 5 \\
\hline
\end{tabular}

TABLE 8: Analysis of necessary conditions.

\begin{tabular}{|c|c|c|c|c|}
\hline \multicolumn{5}{|l|}{ Outcome } \\
\hline \multirow[t]{2}{*}{ Conditions } & \multicolumn{2}{|c|}{$\begin{array}{l}\text { BI (behavioral intention } \\
\text { to accept IoV services) }\end{array}$} & \multicolumn{2}{|c|}{$\begin{array}{l}\sim \mathrm{BI} \text { (negation of } \\
\text { behavioral intention to } \\
\text { accept IoV services) }\end{array}$} \\
\hline & Consistency & Coverage & Consistency & Coverage \\
\hline $\mathrm{PE}$ & 0.932 & 0.841 & 0.734 & 0.494 \\
\hline$\sim \mathrm{PE}$ & 0.439 & 0.689 & 0.764 & 0.893 \\
\hline $\mathrm{EE}$ & 0.931 & 0.827 & 0.745 & 0.493 \\
\hline$\sim \mathrm{EE}$ & 0.430 & 0.693 & 0.739 & 0.888 \\
\hline SI & 0.881 & 0.887 & 0.677 & 0.508 \\
\hline$\sim \mathrm{SI}$ & 0.512 & 0.680 & 0.849 & 0.842 \\
\hline FC & 0.873 & 0.885 & 0.686 & 0.518 \\
\hline$\sim \mathrm{FC}$ & 0.525 & 0.691 & 0.848 & 0.832 \\
\hline HM & 0.910 & 0.880 & 0.695 & 0.501 \\
\hline$\sim \mathrm{HM}$ & 0.484 & 0.680 & 0.833 & 0.874 \\
\hline PV & 0.873 & 0.882 & 0.680 & 0.512 \\
\hline$\sim \mathrm{PV}$ & 0.517 & 0.684 & 0.843 & 0.832 \\
\hline HA & 0.835 & 0.941 & 0.621 & 0.521 \\
\hline$\sim \mathrm{HA}$ & 0.576 & 0.671 & 0.930 & 0.808 \\
\hline PR & 0.552 & 0.752 & 0.747 & 0.759 \\
\hline$\sim \mathrm{PR}$ & 0.823 & 0.813 & 0.756 & 0.557 \\
\hline TR & 0.893 & 0.893 & 0.693 & 0.516 \\
\hline$\sim \mathrm{TR}$ & 0.516 & 0.693 & 0.856 & 0.857 \\
\hline
\end{tabular}

Note: “ " indicates the absence of a condition.

[38] was used. The truth table algorithm proceeds in a twostage analytic procedure, to empirically complete this identification of causal processes. The first step is creating a truth table with $2^{\mathrm{k}}$ ( $\mathrm{k}$ is the number of causal conditions) rows from the fuzzy data, reflecting all possible combinations of causal conditions that lead to a specific outcome ("AI") [58]. The second step involves specifying the causal conditions and outcomes to minimize. The number of rows is reduced in line with two principles: (1) the minimum number of cases (frequency) required for a solution to be considered and (2) the minimum consistency level of a solution [38]. In this study, we set frequency thresholds to be
5 and consistency thresholds to be 0.8 (the actual value was 0.867) to exclude less important configurations; then, the configurations selected captured $82 \%$ of the cases, which meet the recommendation that a threshold is chosen that retains at least $75-80 \%$ of the cases [99].

Based on the "Standard Analyses" procedure, the complex solution, intermediate solution, and parsimonious solution are automatically derived based on the different treatment of the remainder combinations [38], and these solutions can be distinguished based on "easy" and "difficult" counterfactuals [37]. The complex solution includes all possible configurations of conditions (i.e., includes neither easy nor difficult counterfactuals). The parsimonious solution offers vital conditions that can be either easy or difficult counterfactuals. The intermediate solution offers vital conditions based on easy counterfactuals [37]. The notion of causal conditions belonging to the core or peripheral configurations is based on these parsimonious and intermediate solutions: "core" conditions are decisive causal ingredients (those that are part of both parsimonious and intermediate solutions), and "peripheral" conditions are those that are eliminated in the parsimonious solution and thus only appear in the intermediate solution [100]. Table 9 shows the results of fsQCA providing the solution for the outcome (high-level intention to accept IoV-based services) that distinguishes between "core" and "peripheral" conditions.

The results shown in Table 9 indicate none of the isolated antecedent is a sufficient condition for the presence of "AI" and reveal seven equifinal configurations (combinations of conditions linked to the outcome) grouped by their core conditions [100]. All configurations are sufficient because all of the consistency scores resembles the notion of significance in statistical models $[92,102]$ and exceeds the threshold of 0.8 in the sufficiency analysis [38, 99]. Besides, each configuration's coverage, such as an analogous measure of $R^{2}$ in regression analysis [92], is greater than 0 . Thus, all configurations are empirically relevant $[38,44]$. According to the solution coverage value, the overall solution accounts for $86.9 \%$ of the cases associated with high intention to accept IoV-based services.

5.2.4. Analysis of Sufficient Conditions for the Negation of Behavioral Intention to Accept IoV Services. Contrary to most traditional techniques as SEM [104, 105] and regression model $[94,101]$, fsQCA focuses on causal asymmetry $[38,44,91,100]$. FsQCA can be used to analyze separately the configurations for the presence and the absence of an outcome [99]. Therefore, to check this asymmetry, fsQCA conducts another set of analyses in which the negation of behavioral intention to accept IoV services represents the outcome and is coded as the inverse $(\sim \mathrm{BI})$. To explore which conditions consistently lead to this outcome, the same frequency (5) and consistency (0.8, the actual value was $0.858)$ thresholds are set. The solution for the negation of behavioral intention to accept IoV services is shown in Table 10. 
TABLE 9: Sufficient configurations for high intention to accept IoV-based services.

\begin{tabular}{|c|c|c|c|c|c|c|c|c|c|c|c|c|}
\hline \multirow{2}{*}{ Causal condition } & \multicolumn{12}{|c|}{ Solutions } \\
\hline & $1 \mathrm{a}$ & $1 b$ & 2 & $3 a$ & $3 b$ & $3 c$ & $3 \mathrm{~d}$ & 4 & 5 & 6 & $7 \mathrm{a}$ & $7 \mathrm{~b}$ \\
\hline Perceived expectancy & - & - & - & - & - & - & - & $\otimes$ & - & - & $\otimes$ & $\otimes$ \\
\hline Effort expectancy & - & - & $\bullet$ & $\bullet$ & $\bullet$ & - & $\bullet$ & - & & $\otimes$ & & $\otimes$ \\
\hline Social influence & $\bullet$ & $\bullet$ & $\bullet$ & $\bullet$ & $\bullet$ & & $\otimes$ & $\otimes$ & $\otimes$ & $\bullet$ & $\otimes$ & $\otimes$ \\
\hline Facilitating conditions & $\bullet$ & & $\bullet$ & $\bullet$ & & - & $\otimes$ & $\otimes$ & $\otimes$ & $\otimes$ & $\otimes$ & $\otimes$ \\
\hline Hedonic motivation & - & $\bullet$ & & $\bullet$ & $\bullet$ & $\bullet$ & $\bullet$ & $\otimes$ & $\otimes$ & $\bullet$ & $\otimes$ & $\otimes$ \\
\hline Price value & $\otimes$ & $\otimes$ & $\bullet$ & & $\bullet$ & - & $\otimes$ & - & $\otimes$ & $\otimes$ & $\otimes$ & $\otimes$ \\
\hline Habit & $\otimes$ & $\otimes$ & $\bullet$ & & $\bullet$ & $\bullet$ & $\otimes$ & $\bullet$ & $\otimes$ & $\otimes$ & $\otimes$ & $\otimes$ \\
\hline Perceived risk & $\otimes$ & $\otimes$ & $\otimes$ & & & & $\bullet$ & $\otimes$ & $\bullet$ & $\bullet$ & $\otimes$ & $\otimes$ \\
\hline Initial trust & & $\bullet$ & $\otimes$ & $\bullet$ & $\bullet$ & $\bullet$ & $\bullet$ & $\bullet$ & $\otimes$ & $\bullet$ & $\otimes$ & \\
\hline Raw coverage & 0.385 & 0.388 & 0.392 & 0.765 & 0.700 & 0.697 & 0.324 & 0.313 & 0.330 & 0.306 & 0.328 & 0.312 \\
\hline Unique coverage & 0.001 & 0.001 & 0.010 & 0.057 & 0.014 & 0.012 & 0.001 & 0.002 & 0.005 & 0.001 & 0.001 & 0.002 \\
\hline Consistency & 0.963 & 0.964 & 0.985 & 0.943 & 0.971 & 0.973 & 0.974 & 0.983 & 0.941 & 0.979 & 0.859 & 0.860 \\
\hline Solution consistency & \multicolumn{12}{|c|}{0.881} \\
\hline Solution coverage & \multicolumn{12}{|c|}{0.862} \\
\hline
\end{tabular}

Note: black circles ("๑") indicate the presence of a condition, and circles with a cross-out (" $\otimes$ ") indicate its absence. Furthermore, large circles indicate core conditions, and small circles indicate peripheral conditions. Blank spaces indicate a "do not care" situation in which the causal condition may be either present or absent [100].

TABle 10: Sufficient configurations for the negation of high behavioral intention to accept IoV-based services.

\begin{tabular}{|c|c|c|c|c|c|c|c|c|}
\hline \multirow{2}{*}{ Causal condition } & \multicolumn{8}{|c|}{ Solutions } \\
\hline & 1a & $1 b$ & 2 & 3 & 4 & 5 & 6 & 7 \\
\hline Perceived expectancy & $\otimes$ & $\otimes$ & $\otimes$ & ? & ? & ? & - & $\bullet$ \\
\hline Effort expectancy & $\otimes$ & & $\otimes$ & $\bullet$ & $\bullet$ & $\bullet$ & $\bullet$ & $\bullet$ \\
\hline Social influence & $\otimes$ & $\otimes$ & $\otimes$ & $\otimes$ & - & ○ & - & - \\
\hline Facilitating conditions & $\otimes$ & $\otimes$ & $\otimes$ & • & $\otimes$ & $\bullet$ & $\bullet$ & $\bullet$ \\
\hline Hedonic motivation & $\otimes$ & $\otimes$ & $\otimes$ & $\bullet$ & $\bullet$ & $\bullet$ & $\bullet$ & $\bullet$ \\
\hline Habit & $\otimes$ & $\otimes$ & $\otimes$ & $\bullet$ & $\bullet$ & $\otimes$ & & $\bullet$ \\
\hline Price value & $\otimes$ & $\otimes$ & $\otimes$ & $\bullet$ & $\bullet$ & & $\otimes$ & $\bullet$ \\
\hline Perceived risk & & $\otimes$ & $\otimes$ & $\bullet$ & $\otimes$ & & & $\otimes$ \\
\hline Initial trust & $\otimes$ & $\otimes$ & & - & $\bullet$ & • & $\bullet$ & $\otimes$ \\
\hline Raw coverage & 0.586 & 0.494 & 0.468 & 0.424 & 0.468 & 0.506 & 0.554 & 0.468 \\
\hline Unique coverage & 0.115 & 0.010 & 0.004 & 0.004 & 0.008 & 0.003 & 0.017 & 0.002 \\
\hline Consistency & 0.967 & 0.966 & 0.963 & 0.902 & 0.870 & 0.843 & 0.826 & 0.892 \\
\hline Solution consistency & \multicolumn{8}{|c|}{0.794} \\
\hline Solution coverage & \multicolumn{8}{|c|}{0.809} \\
\hline
\end{tabular}

As shown in Table 10, seven identified solutions comply with the recommended consistency and unique coverage thresholds [38]. The overall solution coverage indicates that causal conditions account for $84.4 \%$ of cases in the solution.

\section{Discussion}

6.1. Key Findings. This study aims to show how the analysis of net and combinatory effects of specific antecedent variables can improve the understanding of behavioral intention to accept IoV services [91].

The PLS-SEM results show that performance expectancy $(\beta=0.150)$ has a significantly positive effect on consumers' behavioral intentions. The analysis of necessary conditions of fsQCA also confirms that performance expectancy (consistency $=0.932$ ) is a necessary condition for high behavioral intention. Moreover, $\mathrm{PE}$ is indeed core conditions in nine of the twelve configurations for behavioral intention, reinforcing the findings of PLS-SEM. The relevance of performance expectancy is consistent with the previous studies that highlight the importance of the users' expectancy of performance to achieve the behavioral intention, e.g., autonomous car [7] and autonomous delivery vehicles [45].

Such smart technology usage should be simple and obvious, surprisingly, effort expectancy, as an important functional characteristic of technology, has no significant effect on the behavioral intention from PLS-SEM results. This result is in line with previous research on the acceptance of emerging technologies as smart home [57] and autonomous delivery vehicles [45], but contradicts results from some studies on the adoption of autonomous car [7]. Nevertheless, the results from fsQCA confirm that effort expectancy (consistency $=0.931$ ) is a necessary condition of consumers' behavioral intention. Moreover, it is indeed core conditions in eight of the twelve configurations for behavioral intention, complementing the findings PLS-SEM failed to detect. In such circumstances, IoV-based services and vehicles are not well understood by the users, and they did not 
have sufficient information and they were not familiar with the technology behind the concept. The level of information provided could reduce the perceived complexity, as the less the technology is perceived as complex, the more likely it is that the innovation will be adopted [57].

Different from the significant effect of SI and FC in previous studies $[29,45]$, PLS-SEM results show that neither SI nor FC has a significant "net effect" on behavioral intention to accept IoV, which is aligned with previous studies that find a nonsignificant direct effect of SI on behavioral intention [55, 57], and nonsignificant direct effect of FC on behavioral intention $[54,76]$. Nevertheless, in the fsQCA result, SI is present as a peripheral condition in six of the twelve configurations for BI and is absent as a core condition in four of the eight configurations for the negation of behavioral intention to accept IoV-based services, suggesting the relevance of SI on AI. The result is consistent with numerous studies in IoT [106], Internet banking [75, 76], e-government [71], autonomous vehicle [4, 7, 13], and automated public transport [28]. Besides, the presence of FC is a peripheral condition in four of the twelve configurations for behavioral intention to accept IoV-based services and the absence of FC is a core condition in four of the eight configurations for the negation of behavioral intention to accept IoV-based services, showing the existence of causal asymmetry in a complex context. The result confirms results from previous research carried out on technology acceptance such as mobile banking $[60,64]$ and automated public transport [29]. Overall, the absence of SI and FC as core condition in four solutions for the negation of behavioral intention to accept IoV-based services, especially in solution 3 and solution 4 (the absence of SI or FC, even if all else conditions are present, will determine the outcome the absence of $\mathrm{BI}$ ), indicates that the lower SI and FC about potential consumers, the lower the acceptance of IoV-based services. The results show that IoV-based service/vehicle is a new technology not yet widely adopted and the intention to purchase an innovation is stronger when the innovation is already used by others. Once the concept becomes part of daily life, the impact of SI could be higher.

The PLS-SEM results show that hedonic motivation (HM) does not significantly impact behavioral intention (BI) to use IoV-based services. Nevertheless, fsQCA results indicate that HM is present as a core condition in seven of the twelve configurations for $\mathrm{BI}$ and is absent as a peripheral condition in three of the eight configurations for the negation of BI to accept IoV-based services, suggesting the lowlevel significance of $\mathrm{HM}$ on $\mathrm{BI}$. The finding is contrary to previous studies on the acceptance of autonomous delivery vehicles [45], automated road transport systems [29, 46], social networking service [107], wearable technology [61], and mobile health [58], while it is aligned with some studies such as smart home acceptance [57] and consumer e-loyalty [108]. In summary, IoV services are perceived by connected autonomous vehicle consumers as more of an intelligent utilitarian solution rather than a hedonic one.

Price value (PV) $(\beta=0.153)$ is found to be a significant determinant of behavioral intention (BI) in SEM-PLS results, which is in line with previous research on the acceptance of emerging technologies, e.g., autonomous delivery vehicles [45], autonomous electric bus [31, 48], Internet of things [54], and electric vehicles [65]. This means that consumers consider the benefits of IoV-based services against the monetary value. Furthermore, fsQCA results indicate the absence of $\mathrm{PV}$, as a core condition in four of the eight configurations for the negation of BI to accept IoVbased services, suggesting the low price-performance of consumers' perception on IoV-based services is the barrier of accepting IoV-based services. There is a price premium on IoV-based services compare with the conventional vehicle. Consumers who believe that the price of IoV-based service is justified by the potential benefits have a stronger behavioral intention to adopt. Talebian and Mishra suggest that the automobile will be nearly homogenous in about 2050 only if prices decrease at significant rates (15\% or $20 \%$ annually) [16].

The PLS-SEM results show habit has the strongest effect $(\beta=0.34)$ on behavioral intention, as confirmed in previous studies on the acceptance of emerging technologies, e.g., smart home [57]. Besides, the fsQCA results also confirm that the negation of habit $(\sim \mathrm{HA})$ is a necessary condition (consistency $=0.930)$ for the negation of behavioral intention $(\sim \mathrm{BI})$, and the absence of habit is indeed a core condition in four of the eight configurations for behavioral intention, indicating the lower the habit to use IoV-based services, the less likely it is to accept IoV-based services. Therefore, for the emerging and not widely used technologies, the lack of habit may be the biggest obstacle to technology adoption.

Despite perceived risk has been frequently cited as one major concern in accepting IoV-based services in several studies [3], in this study, PLS-SEM has failed to identify its significant net effect on behavioral intention to accept IoVbased services. This result is aligned with the previous studies, e.g., social commerce [73], e-government [72], autonomous vehicle [32, 34], and connected vehicle [35]. Interestingly, fsQCA results show that the absence of perceived risk is indeed a core condition in six of the twelve configurations for behavioral intention, which corroborates previous studies that observe a negative effect of perceived risk on the adoption of innovative technologies, e.g., mobile payment [59, 77, 109], Internet banking [74-76], IoT in agriculture [70], social media purchase [110], electric vehicles [111, 112], and autonomous vehicle [8, 10, 45, 47]. Previous empirical findings are rather mixed, resulting in the argument that perceived risk cannot be seen as a steady predictor of IoV-based services acceptance [8, 45]. FsQCA results show that perceived risk has been proven as a core condition (an important determinant) in six configurations, indicating the lower the risk perception by potential users, the higher the acceptance of IoV-based services.

It is found from PLS-SEM that the role of initial trust $(\beta=0.41)$ is much stronger in influencing behavioral intention to accept IoV-based services than other perceptual factors. Although "the presence of initial trust" is just a peripheral condition of configuration for behavioral intention, however, "the absence of initial trust" is indeed a core condition in two of the seven configurations for the 
negation of behavioral intention (i.e., the presence of $\mathrm{BI}$ ), suggesting that the lack of initial trust in IoV-based services will also reduce the acceptance intention. The significance of initial trust in shaping behavioral intention corroborates previous studies, e.g., mobile banking [79, 113], cloud technology [114], e-government [72], autonomous vehicles $[8,15,32,34]$, and autonomous shuttle/bus $[31,46,48]$. This finding suggests that trust, as "a tool for the reduction of cognitive complexity," can help to simplify and facilitate the decision-making process, especially in situations with risks and uncertainty $[11,115]$. Therefore, insufficient trust has been thought to be one of the major psychological barriers to the wide adoption of IoV-based services $[15,34]$.

In summary, results from PLS-SEM reveal that higher levels of performance expectancy, price value, habit, and initial trust increase behavioral intention. Moreover, results from fsQCA which is used as a supplementary analysis technique [93] and reinforces the symmetric findings of PLS-SEM, as well as offer additional novel interesting, and more nuanced insights that indicate a combination of the conditions needs to be taken into account to explain the outcome of behavioral intention. Five configurations for "BI" and seven configurations for " $\sim \mathrm{BI}$ " are identified. This synergetic effect could not be captured by PLS-SEM since it examines the condition in isolation from the other conditions $[44,92]$.

6.2. Theoretical Implications. This study has two key theoretical contributions. Firstly, this study takes an integrated approach towards technology acceptance in the context of the IoV-based services, which complements and extends technology acceptance studies. As different theories emphasize the different insights regarding technology acceptance, most researchers have called for a holistic and comprehensive approach that integrates more than one single theoretical perspective for understanding the acceptance of innovative technologies $[31,46,64,116]$, to make full use of the advantages of different models, and make up the deficiency of the one-sidedness from a single model. Therefore, to provide broad coverage of factors for IoVbased services acceptance, this study answers this call by developing an integrated model incorporating UTAUT, perceived risk theory, and initial trust model. The net effect analysis of this integrated model shows an explained variance $\left(R^{2}\right)$ of $78 \%$ for behavioral intention to accept IoV services, indicating a moderate explanatory power.

Secondly, this study contributes to the IoV-based services' acceptance literature at the methodological level. Existing studies on the topic generally rely on multiple regression models, SEM, and PLS methodology and view consumer's intention to accept IoV-based services primarily as the outcome of several isolated antecedents. Besides the PLS-SEM, the study uses the fsQCA to investigate which configurations of determinants lead to the intention to accept IoV-based services and which ones lead to the negation of intention to accept IoV-based services. To the best of our knowledge, this study is the first to use this type of analysis to explore the intention to accept IoV-based services. This study demonstrates that the fsQCA offers much in terms of understanding how various determinants explain the acceptance of IoV-based services, more so than the PLS-SEM. Besides, this study by fsQCA also answers the call for the application of this technique to complex behavior research, since it can offer new insights into understanding the IoV-based services acceptance phenomena [44, 94]. Therefore, the value of this study lies in the effort to describe combinatorial complexities assuming asymmetrical relationships between variables, rather than symmetrical net effects that PLS-SEM estimates [105].

6.3. Managerial Implications. From a practical point of view, this study's findings provide several managerial implications for automobile manufacturers, marketers, and policymakers. Based on our findings of PLS-SEM and fsQCA, they should focus on different configurations of antecedents that give rise to an outcome, rather than the impact of these antecedents isolation from each other.

First, as suggested by our findings of PLS-SEM and fsQCA, both the utilitarian benefits (i.e., performance expectancy, and effort expectancy) and hedonic benefits are favored by potential users. Hence, automobile manufacturers and marketers should focus more on the development and the marketing communication activities of IoV-based services on the utilitarian benefits and hedonic benefits compared to conventional vehicles. Moreover, lower perceived risk is also found to contribute to IoV-based services acceptance to a large extent. Besides, if potential risks are not well understood thoughtfully, they could slow IoV-based services adoption rates to socially suboptimal levels. Therefore, marketers should take perceived risk reduction into consideration when promoting IoV-based services in society. Most importantly, high quality and low price, the best cost effective. Price is the most stimulating and sensitive factor influencing consumers' purchasing behavior. Sell IoV-based services at a premium decreased consumers' willingness to pay, hence, manufacturers and sellers should give consumers discounts and cut prices to more reasonable levels.

Second, habit and initial trust is a major construct for explaining the adoption of IoV-based services, with the first and second-largest effect, respectively, and meanwhile, the lack of habit and initial trust is likely to lead to the lower intention to accept IoV-based services. As IoVbased services are in its initial stage, manufacturers, marketers, and policymakers should be more concerned about the measures to increase the individuals' habit and initial trust toward this innovative technology. Therefore, consumers' habit formation and trust building become an urgent mission for these stakeholders [8]. For instance, exhibitions and user experience activities of IoV-based technologies and services should be held to help consumers observe and directly experience IoV-based services, such experiences and knowledge are conducive to the formation of habit and trust toward IoV-based services [80] and are critical ingredients for widespread and rapid technology diffusion [53]. 
Finally, the lower level of social influence and facilitating conditions also lead to a lower level of behavioral intention to accept IoV services. When the individuals' knowledge levels about a specific technology are low or the technology is still in its initial stages, and public communication significantly influences societal acceptance [8]. For the acceptance of IoV-based services, it is of particular relevance to what the social environment (i.e., family, friends, and acquaintances) thinks, what the media reports, and what opinion experts reflect [16]. Hence, marketers might use social influence when promoting IoV-based services during the market introduction stage.

6.4. Limitations and Future Directions. Our study has several limitations that could be addressed in the future. First, we did not take into account other factors that might affect consumers' intention to accept or purchase IoV-based services. Our model based on UTAUT2, perceived risk theory, and initial trust theory only considers some important factors, but it is far from reaching a comprehensive explanation. In the future, the extent to which consumers' purchase intentions are affected can be explored based on other consumer behavior and technology adoption theories that match the characteristics of IoV-based services. Second, this study uses data collected through a purposive sample in a single country, China, which implies that our findings reflect only the situation in this nation, and may affect the generalization of our findings due to differences in the cultural environment and political system of countries. Therefore, a future study may consider a comparative study across different countries, e.g., the U.S. of North America, Germany of Europe, Japan, South Korea, and India of the Asian-Pacific region, and Brazil of South America.

\section{Conclusions}

IoV-based services, as radical innovations for changing transportation fundamentally, introduce all sorts of different benefits such as safety, energy efficiency, environment improvement, increased mobility, and more entertainment in driving $[3-5,9,14]$. IoV-based services are not widely accepted by consumers without understanding IoV-based services diffusion. Thus, investigation of the determinants leading to consumers' intention to accept and purchase IoVbased services is significant for both academics and practitioners. This study identifies the determinants of behavioral intention to accept IoV services by using an integrated model that combines UTAUT, perceived risk theory, and initial trust theory. This study uses both symmetric (PLSSEM) and asymmetric (fsQCA) methods to explore the role of determinants in consumers' intention to accept and purchase IoV-based services. Specifically, the net effects of each antecedent factor on intention are analyzed by conventional correlational techniques (PLS-SEM). The direct effects of performance expectancy, price value, habit, and initial trust on intention are found to be significant. Despite the determinants (e.g., effort expectancy, social influence, facilitating conditions, hedonic motivation, and perceived risk) are found to be nonsignificant effects on intention, however, it cannot be said they are not important to intention to accept IoV-based services, due to the existence of causal complexity. For the high levels of causal complexity, fsQCA provides a more nuanced understanding of how these antecedent conditions fit together to affect consumers' intention to accept and purchase IoV-based services. The results from fsQCA provide twelve different configurations to achieve high levels of behavioral intention to accept IoV services and eight causal paths equifinally to lead to the negation of behavioral intention to accept IoV services. The findings provide relevant insights and marketing suggestions for incentivizing consumers to accept IoV-based services.

\section{Data Availability}

The data used to support the findings of this study are available from the corresponding author upon request.

\section{Conflicts of Interest}

The authors declare that there are no conflicts of interest regarding the publication of this paper.

\section{Acknowledgments}

This research was funded by the National Social Science Fund of China (20FGLB070), Shandong Provincial Natural Science Foundation of China (ZR2019BG004), Shandong Provincial Humanities and Social Sciences Research Program for University of China (J18RA047), and National Natural Science Foundation of China (72072103).

\section{References}

[1] S. E. Shladover, "Connected and automated vehicle systems: introduction and overview," Journal of Intelligent Transportation Systems, vol. 22, no. 3, pp. 190-200, 2018.

[2] J. Wu, H. Liao, J.-W. Wang, and T. Chen, "The role of environmental concern in the public acceptance of autonomous electric vehicles: a survey from China," Transportation Research Part F: Traffic Psychology and Behaviour, vol. 60, pp. 37-46, 2019.

[3] J. Wu, H. Liao, and J.-W. Wang, "Analysis of consumer attitudes towards autonomous, connected, and electric vehicles: a survey in China," Research in Transportation Economics, vol. 80, Article ID 100828, 2020.

[4] N. Adnan, S. Md Nordin, M. A. Bin Bahruddin, and M. Ali, "How trust can drive forward the user acceptance to the technology? In-vehicle technology for autonomous vehicle," Transportation Research Part A: Policy and Practice, vol. 118, pp. 819-836, 2018.

[5] P. Bansal and K. M. Kockelman, "Forecasting Americans' long-term adoption of connected and autonomous vehicle technologies," Transportation Research Part A: Policy and Practice, vol. 95, pp. 49-63, 2017.

[6] F. Becker and K. W. Axhausen, "Literature review on surveys investigating the acceptance of automated vehicles," Transportation, vol. 44, no. 6, pp. 1293-1306, 2017.

[7] T. Leicht, A. Chtourou, and K. Ben Youssef, "Consumer innovativeness and intentioned autonomous car adoption," 
The Journal of High Technology Management Research, vol. 29, no. 1, pp. 1-11, 2018.

[8] H. Liu, R. Yang, L. Wang, and P. Liu, "Evaluating initial public acceptance of highly and fully autonomous vehicles," International Journal of Human-Computer Interaction, vol. 35, no. 11, pp. 919-931, 2019.

[9] M.-K. Kim, J.-H. Park, J. Oh, W.-S. Lee, and D. Chung, "Identifying and prioritizing the benefits and concerns of connected and autonomous vehicles: a comparison of individual and expert perceptions," Research in Transportation Business \& Management, vol. 32, Article ID 100438, 2019.

[10] G. Zhu, Y. Chen, and J. Zheng, "Modelling the acceptance of fully autonomous vehicles: a media-based perception and adoption model," Transportation Research Part F: Traffic Psychology and Behaviour, vol. 73, pp. 80-91, 2020.

[11] T. Zhang, D. Tao, X. Qu, X. Zhang, R. Lin, and W. Zhang, "The roles of initial trust and perceived risk in public's acceptance of automated vehicles," Transportation Research Part C: Emerging Technologies, vol. 98, pp. 207-220, 2019.

[12] J. M. Müller, "Comparing technology acceptance for autonomous vehicles, battery electric vehicles, and car sharinga study across Europe, China, and North America," Sustainability, vol. 11, no. 16, Article ID 4333, 2019.

[13] I. Panagiotopoulos and G. Dimitrakopoulos, "An empirical investigation on consumers' intentions towards autonomous driving," Transportation Research Part C: Emerging Technologies, vol. 95, pp. 773-784, 2018.

[14] K. F. Yuen, G. Chua, X. Wang, F. Ma, and K. X. Li, "Understanding public acceptance of autonomous vehicles using the theory of planned behaviour," International Journal of Environmental Research and Public Health, vol. 17, no. 12, Article ID 4419, 2020.

[15] S. M. Hegner, A. D. Beldad, and G. J. Brunswick, "In automatic we trust: investigating the impact of trust, control, personality characteristics, and extrinsic and intrinsic motivations on the acceptance of autonomous vehicles," International Journal of Human-Computer Interaction, vol. 35, no. 19, pp. 1769-1780, 2019.

[16] A. Talebian and S. Mishra, "Predicting the adoption of connected autonomous vehicles: a new approach based on the theory of diffusion of innovations," Transportation Research Part C: Emerging Technologies, vol. 95, pp. 363-380, 2018.

[17] T. H. Rashidi, A. Najmi, A. Haider, C. Wang, and F. Hosseinzadeh, "What we know and do not know about connected and autonomous vehicles," Transportmetrica A: Transport Science, vol. 16, no. 3, pp. 987-1029, 2020.

[18] F. Yang, J. Li, T. Lei, and S. Wang, "Architecture and key technologies for internet of vehicles: a survey," Journal of Communications and Information Networks, vol. 2, no. 2, pp. 1-17, 2017.

[19] K. M. Alam, M. Saini, and A. E. Saddik, "Toward social internet of vehicles: concept, architecture, and applications," IEEE Access, vol. 3, pp. 343-357, 2015.

[20] J. Contreras-Castillo, S. Zeadally, and J. A. Guerrero-Ibañez, "Internet of vehicles: architecture, protocols, and security," IEEE Internet of Things Journal, vol. 5, no. 5, pp. 3701-3709, 2018.

[21] O. Kaiwartya, A. H. Abdullah, Y. Cao et al., "Internet of vehicles: motivation, layered architecture, network model, challenges, and future aspects," IEEE Access, vol. 4, pp. 5356-5373, 2016.

[22] J. Cheng, J. Cheng, M. Zhou, F. Liu, S. Gao, and C. Liu, "Routing in internet of vehicles: a review," IEEE Transactions on Intelligent Transportation Systems, vol. 16, no. 5, pp. 2339-2352, 2015.

[23] M. Chen, Y. Tian, G. Fortino, J. Zhang, and I. Humar, "Cognitive internet of vehicles," Computer Communications, vol. 120, pp. 58-70, 2018.

[24] A. Shariff, J.-F. Bonnefon, and I. Rahwan, "Psychological roadblocks to the adoption of self-driving vehicles," Nature Human Behaviour, vol. 1, no. 10, pp. 694-696, 2017.

[25] M. Guériau, R. Billot, N.-E. El Faouzi, J. Monteil, F. Armetta, and S. Hassas, "How to assess the benefits of connected vehicles? a simulation framework for the design of cooperative traffic management strategies," Transportation Research Part C: Emerging Technologies, vol. 67, pp. 266-279, 2016.

[26] P. Jing, G. Xu, Y. Chen, Y. Shi, and F. Zhan, "The determinants behind the acceptance of autonomous vehicles: a systematic review," Sustainability, vol. 12, no. 5, Article ID 1719, 2020.

[27] J. Zmud, I. N. Sener, and J. Wagner, "Self-driving vehicles: determinants of adoption and conditions of usage," Transportation Research Record: Journal of the Transportation Research Board, vol. 2565, no. 1, pp. 57-64, 2016.

[28] R. Madigan, T. Louw, M. Dziennus et al., "Acceptance of automated road transport systems (ARTS): an adaptation of the UTAUT model," Transportation Research Procedia, vol. 14, pp. 2217-2226, 2016.

[29] R. Madigan, T. Louw, M. Wilbrink, A. Schieben, and N. Merat, "What influences the decision to use automated public transport? using UTAUT to understand public acceptance of automated road transport systems," Transportation Research Part F: Traffic Psychology and Behaviour, vol. 50, pp. 55-64, 2017.

[30] S. Deb, L. Strawderman, D. W. Carruth, J. DuBien, B. Smith, and T. M. Garrison, "Development and validation of a questionnaire to assess pedestrian receptivity toward fully autonomous vehicles," Transportation Research Part C: Emerging Technologies, vol. 84, pp. 178-195, 2017.

[31] B. Herrenkind, I. Nastjuk, A. B. Brendel, S. Trang, and L. M. Kolbe, "Young people's travel behavior-using the lifeoriented approach to understand the acceptance of autonomous driving," Transportation Research Part D: Transport and Environment, vol. 74, pp. 214-233, 2019.

[32] J. K. Choi and Y. G. Ji, "Investigating the importance of trust on adopting an autonomous vehicle," International Journal of Human-Computer Interaction, vol. 31, no. 10, pp. 692-702, 2015.

[33] J. Kim, S. Kim, and C. Nam, "User resistance to acceptance of In-Vehicle Infotainment (IVI) systems," Telecommunications Policy, vol. 40, no. 9, pp. 919-930, 2016.

[34] P. Liu, Q. Guo, F. Ren, L. Wang, and Z. Xu, "Willingness to pay for self-driving vehicles: influences of demographic and psychological factors," Transportation Research Part C: Emerging Technologies, vol. 100, pp. 306-317, 2019.

[35] J. Walter and B. Abendroth, "On the role of informational privacy in connected vehicles: a privacy-aware acceptance modelling approach for connected vehicular services," Telematics and Informatics, vol. 49, Article ID 101361, 2020.

[36] J. Chaparro-Peláez, Á. F. Agudo-Peregrina, and F. J. PascualMiguel, "Conjoint analysis of drivers and inhibitors of e-commerce adoption," Journal of Business Research, vol. 69, no. 4, pp. 1277-1282, 2016.

[37] B. Kaya, A. M. Abubakar, E. Behravesh, H. Yildiz, and I. S. Mert, “Antecedents of innovative performance: findings 
from PLS-SEM and fuzzy sets (fsQCA)," Journal of Business Research, vol. 114, pp. 278-289, 2020.

[38] C. C. Ragin, Redesigning Social Inquiry: Fuzzy Sets and Beyond, University of Chicago Press, Chicago, IL, USA, 2008.

[39] B. Rihoux and C. C. Ragin, Configurational Comparative Methods: Qualitative Comparative Analysis (QCA) and Related Techniques, Sage Publications, Thousand Oaks, CA, USA, 2009.

[40] A. G. Woodside, "Moving beyond multiple regression analysis to algorithms: calling for adoption of a paradigm shift from symmetric to asymmetric thinking in data analysis and crafting theory," Journal of Business Research, vol. 66, no. 4, pp. 463-472, 2013.

[41] V. Venkatesh, J. Y. L. Thong, and X. Xu, "Consumer acceptance and use of information technology: extending the unified theory of acceptance and use of technology," MIS Quarterly, vol. 36, no. 1, pp. 157-178, 2012.

[42] J. W. Taylor, "The role of risk in consumer behavior," Journal of Marketing, vol. 38, no. 2, pp. 54-60, 1974.

[43] D. H. McKnight, V. Choudhury, and C. Kacmar, "Developing and validating trust measures for e-Commerce: an integrative typology," Information Systems Research, vol. 13, no. 3, pp. 334-359, 2002.

[44] S. F. Jahanmir, G. M. Silva, P. J. Gomes, and H. M. Gonçalves, "Determinants of users' continuance intention toward digital innovations: are late adopters different?" Journal of Business Research, vol. 115, pp. 225-233, 2020.

[45] S. Kapser and M. Abdelrahman, "Acceptance of autonomous delivery vehicles for last-mile delivery in Germany-extending UTAUT2 with risk perceptions," Transportation Research Part C: Emerging Technologies, vol. 111, pp. 210-225, 2020.

[46] C.-F. Chen, "Factors affecting the decision to use autonomous shuttle services: evidence from a scooter-dominant urban context," Transportation Research Part F: Traffic Psychology and Behaviour, vol. 67, pp. 195-204, 2019.

[47] J. Lee, D. Lee, Y. Park, S. Lee, and T. Ha, "Autonomous vehicles can be shared, but a feeling of ownership is important: examination of the influential factors for intention to use autonomous vehicles," Transportation Research Part C: Emerging Technologies, vol. 107, pp. 411-422, 2019.

[48] B. Herrenkind, A. B. Brendel, I. Nastjuk, M. Greve, and L. M. Kolbe, "Investigating end-user acceptance of autonomous electric buses to accelerate diffusion," Transportation Research Part D: Transport and Environment, vol. 74, pp. 255-276, 2019.

[49] M. Fishbein and I. Ajzen, Belief, Attitude, Intention, and Behavior: An Introduction to Theory and Research, AddisonWesley Publishing Company, Boston, MA, USA, 1975.

[50] F. D. Davis, "Perceived usefulness, perceived ease of use, and user acceptance of information technology," MIS Quarterly, vol. 13, no. 3, pp. 319-340, 1989.

[51] I. Ajzen, "The theory of planned behavior," Organizational Behavior and Human Decision Processes, vol. 50, no. 2, pp. 179-211, 1991.

[52] V. Venkatesh, M. G. Morris, G. B. Davis, and F. D. Davis, "User acceptance of information technology: toward a unified view," MIS Quarterly, vol. 27, no. 3, pp. 425-478, 2003.

[53] E. M. Rogers, Diffusion of Innovations, Simon \& Schuster, New York, NY, USA, 4th edition, 2020.

[54] M. Q. Aldossari and A. Sidorova, "Consumer acceptance of Internet of things (IoT): smart home context," Journal of Computer Information Systems, vol. 60, no. 6, pp. 507-517, 2020.
[55] M. A. Almaiah, M. M. Alamri, and W. Al-Rahmi, "Applying the UTAUT model to explain the students' acceptance of Mobile learning system in higher education," IEEE Access, vol. 7, pp. 174673-174686, 2019.

[56] M. Shorfuzzaman and M. Alhussein, “Modeling learners' readiness to adopt mobile learning: a perspective from a GCC higher education institution," Mobile Information Systems, vol. 2016, Article ID 6982824, , 2016.

[57] P. Baudier, C. Ammi, and M. Deboeuf-Rouchon, "Smart home: highly-educated students' acceptance," Technological Forecasting and Social Change, vol. 153, Article ID 119355, 2020.

[58] P. Duarte and J. C. Pinho, "A mixed methods UTAUT2based approach to assess mobile health adoption," Journal of Business Research, vol. 102, pp. 140-150, 2019.

[59] Q. Cao and X. Niu, "Integrating context-awareness and UTAUT to explain Alipay user adoption," International Journal of Industrial Ergonomics, vol. 69, pp. 9-13, 2019.

[60] T. Zhou, Y. Lu, and B. Wang, "Integrating TTF and UTAUT to explain mobile banking user adoption," Computers in Human Behavior, vol. 26, no. 4, pp. 760-767, 2010.

[61] Y. Gao, H. Li, and Y. Luo, "An empirical study of wearable technology acceptance in healthcare," Industrial Management \& Data Systems, vol. 115, no. 9, pp. 1704-1723, 2015.

[62] F. Liao, E. Molin, and B. van Wee, "Consumer preferences for electric vehicles: a literature review," Transport Reviews, vol. 37, no. 3, pp. 252-275, 2017.

[63] P. Bansal, K. M. Kockelman, and A. Singh, "Assessing public opinions of and interest in new vehicle technologies: an Austin perspective," Transportation Research Part C: Emerging Technologies, vol. 67, pp. 1-14, 2016.

[64] T. Oliveira, M. Faria, M. A. Thomas, and A. Popovič, "Extending the understanding of mobile banking adoption: when UTAUT meets TTF and ITM," International Journal of Information Management, vol. 34, no. 5, pp. 689-703, 2014.

[65] K. Degirmenci and M. H. Breitner, "Consumer purchase intentions for electric vehicles: is green more important than price and range?" Transportation Research Part D: Transport and Environment, vol. 51, pp. 250-260, 2017.

[66] G. Cecere, N. Corrocher, and M. Guerzoni, "Price or performance? a probabilistic choice analysis of the intention to buy electric vehicles in European countries," Energy Policy, vol. 118, pp. 19-32, 2018.

[67] N. Adnan, S. Md Nordin, M. Hadi Amini, and N. Langove, "What make consumer sign up to PHEVs? predicting Malaysian consumer behavior in adoption of PHEVs," Transportation Research Part A: Policy and Practice, vol. 113, pp. 259-278, 2018.

[68] A. Hong, C. Nam, and S. Kim, "What will be the possible barriers to consumers' adoption of smart home services?" Telecommunications Policy, vol. 44, no. 2, Article ID 101867, 2020.

[69] Y. Liang, G. Qi, K. Wei, and J. Chen, "Exploring the determinant and influence mechanism of e-Government cloud adoption in government agencies in China," Government Information Quarterly, vol. 34, no. 3, pp. 481-495, 2017.

[70] P. Jayashankar, S. Nilakanta, W. J. Johnston, P. Gill, and R. Burres, "IoT adoption in agriculture: the role of trust, perceived value and risk," Journal of Business \& Industrial Marketing, vol. 33, no. 6, pp. 804-821, 2018.

[71] Q. Xie, W. Song, X. Peng, and M. Shabbir, "Predictors for e-government adoption: integrating TAM, TPB, trust and perceived risk," The Electronic Library, vol. 35, no. 1, pp. 2-20, 2017. 
[72] F. Bélanger and L. Carter, "Trust and risk in e-government adoption," The Journal of Strategic Information Systems, vol. 17, no. 2, pp. 165-176, 2008.

[73] S. T. Biucky, N. Abdolvand, and S. Rajaee Harandi, "The effects of perceived risk on social commerce adoption based on the tam model," International Journal of Electronic Commerce Studies, vol. 8, no. 2, pp. 173-196, 2017.

[74] M.-C. Lee, "Factors influencing the adoption of internet banking: an integration of TAM and TPB with perceived risk and perceived benefit," Electronic Commerce Research and Applications, vol. 8, no. 3, pp. 130-141, 2009.

[75] A. Kesharwani and S. Singh Bisht, "The impact of trust and perceived risk on internet banking adoption in India," International Journal of Bank Marketing, vol. 30, no. 4, pp. 303-322, 2012.

[76] C. Martins, T. Oliveira, and A. Popovič, "Understanding the Internet banking adoption: a unified theory of acceptance and use of technology and perceived risk application," International Journal of Information Management, vol. 34, no. 1, pp. 1-13, 2014.

[77] R. Thakur and M. Srivastava, “Adoption readiness, personal innovativeness, perceived risk and usage intention across customer groups for mobile payment services in India," Internet Research, vol. 24, no. 3, pp. 369-392, 2014.

[78] R. P. Q. Falcao, J. B. Ferreira, and M. Carrazedo Marques da Costa Filho, "The influence of ubiquitous connectivity, trust, personality and generational effects on mobile tourism purchases," Information Technology \& Tourism, vol. 21, no. 4, pp. 483-514, 2019.

[79] T. Zhou, "An empirical examination of initial trust in mobile banking," Internet Research, vol. 21, no. 5, pp. 527-540, 2011.

[80] D. H. Mcknight, M. Carter, J. B. Thatcher, and P. F. Clay, "Trust in a specific technology," ACM Transactions on Management Information Systems, vol. 2, no. 2, pp. 1-25, 2011.

[81] J. F. Hair, J. J. Risher, M. Sarstedt, and C. M. Ringle, "When to use and how to report the results of PLS-SEM," European Business Review, vol. 31, no. 1, pp. 2-24, 2019.

[82] R. W. Brislin, "Back-translation for cross-cultural research," Journal of Cross-Cultural Psychology, vol. 1, no. 3, pp. 185216, 1970.

[83] P. A. Pavlou, "Consumer acceptance of electronic commerce: integrating trust and risk with the technology acceptance model," International Journal of Electronic Commerce, vol. 7, no. 3, pp. 101-134, 2003.

[84] J. S. Armstrong and T. S. Overton, "Estimating nonresponse bias in mail surveys," Journal of Marketing Research, vol. 14, no. 3, pp. 396-402, 1977.

[85] N. Urbach and A. Frederik, "Structural equation modeling in information systems research using partial least squares," Journal of Information Technology Theory and Application, vol. 11, no. 2, pp. 5-40, 2010.

[86] P. Mikalef, M. Boura, G. Lekakos, and J. Krogstie, "The role of information governance in big data analytics driven innovation," Information \& Management, vol. 57, no. 7, Article ID 103361, 2020.

[87] Y. Zhang, J. Sun, Z. Yang, and Y. Wang, "What makes people actually embrace or shun mobile payment: a cross-culture study," Mobile Information Systems, vol. 2018, Article ID 7497545, 13 pages, 2018.

[88] P. M. Podsakoff, S. B. MacKenzie, and N. P. Podsakoff, "Sources of method bias in social science research and recommendations on how to control it," Annual Review of Psychology, vol. 63, no. 1, pp. 539-569, 2012.
[89] N. Kock, "Common method bias in PLS-SEM," International Journal of e-Collaboration, vol. 11, no. 4, pp. 1-10, 2015.

[90] Y. Liang, G. Qi, X. Zhang, and G. Li, "The effects of e-Government cloud assimilation on public value creation: an empirical study of China," Government Information Quarterly, vol. 36, no. 4, Article ID 101397, 2019.

[91] C. Afonso, G. M. Silva, H. M. Gonçalves, and M. Duarte, "The role of motivations and involvement in wine tourists" intention to return: SEM and fsQCA findings," Journal of Business Research, vol. 89, pp. 313-321, 2018.

[92] P. Mikalef and A. Pateli, "Information technology-enabled dynamic capabilities and their indirect effect on competitive performance: findings from PLS-SEM and fsQCA," Journal of Business Research, vol. 70, pp. 1-16, 2017.

[93] M. A. Stanko, "Toward a theory of remixing in online innovation communities," Information Systems Research, vol. 27, no. 4, pp. 773-791, 2016.

[94] Y. Liu, J. Mezei, V. Kostakos, and H. Li, “Applying configurational analysis to IS behavioural research: a methodological alternative for modelling combinatorial complexities," Information Systems Journal, vol. 27, no. 1, pp. 59-89, 2017.

[95] C. M. Ringle, M. Sarstedt, and D. W. Straub, "Editor's comments: a critical look at the use of PLS-SEM in MIS quarterly," Management Information Systems Quarterly, vol. 36, no. 1, 2012.

[96] C. Fornell and D. F. Larcker, "Evaluating structural equation models with unobservable variables and measurement Error," Journal of Marketing Research, vol. 18, no. 1, pp. 39-50, 1981.

[97] J. F. Hair, C. M. Ringle, and M. Sarstedt, "PLS-SEM: indeed a silver bullet," Journal of Marketing Theory and Practice, vol. 19, no. 2, pp. 139-152, 2011.

[98] W. W. Chin, "The partial least squares approach to structural equation modeling," Modern Methods for Business Research, vol. 295 , no. 2 , pp. $295-336,1998$.

[99] T. Greckhamer, S. Furnari, P. C. Fiss, and R. V. Aguilera, "Studying configurations with qualitative comparative analysis: best practices in strategy and organization research," Strategic Organization, vol. 16, no. 4, pp. 482-495, 2018.

[100] P. C. Fiss, "Building better causal theories: a fuzzy set approach to typologies in organization research," Academy of Management Journal, vol. 54, no. 2, pp. 393-420, 2011.

[101] I. O. Pappas, S. Papavlasopoulou, P. Mikalef, and M. N. Giannakos, "Identifying the combinations of motivations and emotions for creating satisfied users in SNSs: an fsQCA approach," International Journal of Information Management, vol. 53, Article ID 102128, 2020.

[102] C. Q. Schneider and C. Wagemann, "Standards of good practice in qualitative comparative analysis (QCA) and fuzzy-sets," Comparative Sociology, vol. 9, no. 3, pp. 397-418, 2010.

[103] N. Del Sarto, D. A. Isabelle, and A. Di Minin, "The role of accelerators in firm survival: an fsQCA analysis of Italian startups," Technovation, vol. 90-91, Article ID 102102, 2020.

[104] A. Urueña and A. Hidalgo, "Successful loyalty in e-complaints: FsQCA and structural equation modeling analyses," Journal of Business Research, vol. 69, no. 4, pp. 1384-1389, 2016.

[105] T.-H. Jiang, S.-L. Chen, and J. K. C. Chen, "Examining the role of behavioral intention on multimedia teaching materials using FSQCA," Journal of Business Research, vol. 69, no. 6, pp. 2252-2258, 2016. 
[106] L. Gao and X. Bai, "A unified perspective on the factors influencing consumer acceptance of internet of things technology," Asia Pacific Journal of Marketing and Logistics, vol. 26, no. 2, pp. 211-231, 2014.

[107] S. Choi, "The flipside of ubiquitous connectivity enabled by smartphone-based social networking service: social presence and privacy concern," Computers in Human Behavior, vol. 65, pp. 325-333, 2016.

[108] J. Fang, Y. Shao, and C. Wen, "Transactional quality, relational quality, and consumer e-loyalty: evidence from SEM and fsQCA," International Journal of Information Management, vol. 36, no. 6, pp. 1205-1217, 2016.

[109] J. Li, J. Wang, S. Wangh, and Y. Zhou, "Mobile payment with Alipay: an application of extended technology acceptance model," IEEE Access, vol. 7, pp. 50380-50387, 2019.

[110] D. D. Gunawan and K.-H. Huarng, "Viral effects of social network and media on consumers' purchase intention," Journal of Business Research, vol. 68, no. 11, pp. 2237-2241, 2015.

[111] S. Wang, J. Wang, J. Li, J. Wang, and L. Liang, "Policy implications for promoting the adoption of electric vehicles: do consumer's knowledge, perceived risk and financial incentive policy matter?" Transportation Research Part A: Policy and Practice, vol. 117, pp. 58-69, 2018.

[112] L. Qian and J. Yin, "Linking Chinese cultural values and the adoption of electric vehicles: the mediating role of ethical evaluation," Transportation Research Part D: Transport and Environment, vol. 56, pp. 175-188, 2017.

[113] T. Zhou, "Examining mobile banking user adoption from the perspectives of trust and flow experience," Information Technology and Management, vol. 13, no. 1, pp. 27-37, 2012.

[114] S. M. Ho, M. Ocasio-Velázquez, and C. Booth, "Trust or consequences? causal effects of perceived risk and subjective norms on cloud technology adoption," Computers \& Security, vol. 70, pp. 581-595, 2017.

[115] D. J. Kim, D. L. Ferrin, and H. R. Rao, “A trust-based consumer decision-making model in electronic commerce: the role of trust, perceived risk, and their antecedents," Decision Support Systems, vol. 44, no. 2, pp. 544-564, 2008.

[116] R. Martins, T. Oliveira, and M. A. Thomas, "An empirical analysis to assess the determinants of SaaS diffusion in firms," Computers in Human Behavior, vol. 62, pp. 19-33, 2016. 